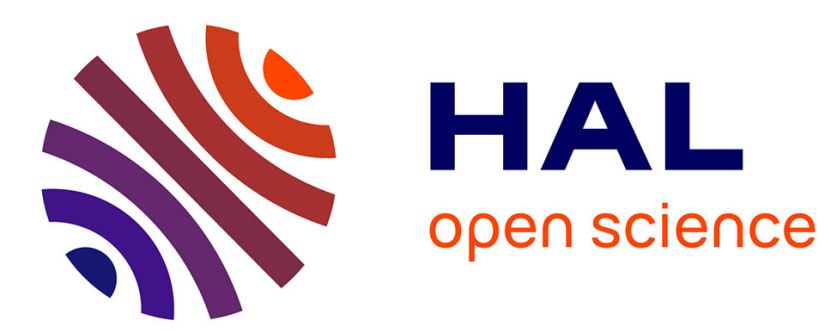

\title{
Numerical modeling of an in-vessel flow limiter using an immersed boundary approach
}

\author{
Michel Belliard
}

\section{To cite this version:}

Michel Belliard. Numerical modeling of an in-vessel flow limiter using an immersed boundary approach. Nuclear Engineering and Design, 2018, 330, pp.437-449. hal-02047738

\section{HAL Id: hal-02047738 \\ https://hal.science/hal-02047738}

Submitted on 25 Feb 2019

HAL is a multi-disciplinary open access archive for the deposit and dissemination of scientific research documents, whether they are published or not. The documents may come from teaching and research institutions in France or abroad, or from public or private research centers.
L'archive ouverte pluridisciplinaire HAL, est destinée au dépôt et à la diffusion de documents scientifiques de niveau recherche, publiés ou non, émanant des établissements d'enseignement et de recherche français ou étrangers, des laboratoires publics ou privés. 


\title{
Numerical modeling of an in-vessel flow limiter using an Immersed Boundary Approach
}

\author{
Michel Belliard* \\ French Atomic Energy Commission (CEA) \\ CEA/DEN/DER/SESI/LEMS, Centre de Cadarache, Bât. 1222, F-13108 \\ Saint-Paul-lez-Durance Cedex, France
}

\begin{abstract}
This work is in the context of the mitigation of the consequences of a large-break loss of coolant accident in a pressurized water reactor. To minimize the flow leaving the vessel and prevent or delay the uncovering of the core, CEA has devised a device, named in-vessel flow limiter, limiting the flow of fluid from the vessel to the break. The goal is to interfere as little as possible with the nominal operation flow and maximize the fluid retained in the event of this kind of accident.

In order to quickly perform a series of 3D-CFD simulations to optimize this device, it is imperative to have a simulation tool that provides sufficiently accurate results in a reasonable time. For this goal, an immersed boundary condition approach is retained. The solid obstacles constituted by the fins of the device are not extruded from the fluid domain, but included in the calculation domain itself. Their presence is considered by a local forcing term.

Through 3D/1D up-scaling of CFD global quantities, local pressure-drop coefficients, induced by the in-vessel flow limiter, can be provided to thermalhydraulic system safety codes. It allows safety studies of the thermal-hydraulic system taking into account the in-vessel flow limiter presence in a more realistic way.

Key words: In-vessel flow limiter, Thermal-hydraulic system safety, CATHARE, CFD, GENEPI, Immersed Boundary Method
\end{abstract}




\section{Introduction - Context}

The context of this work is set in the domain of Generation II and III nuclear power plants. Generation II reactors are the class of commercial reactors that was built by the end of the 1990s and that includes several types of de5 sign: PWR, BWR, CANDU, AGR and VVER. Generation III reactors are the innovative designs that are under construction or still in design phase: EPR, ATMEA1, AP1000, APR1400, ESBWR, ... 1. More specifically, we focused on the light-water Pressurized Water Reactors (PWRs), which are the main type of reactors built and exploited in France. Nowadays passive safety systems are more and more included in the nuclear-reactor safety strategy to mitigate design basis accidents (for example AP600 and AP1000 [1]; see also 2]). A passive safety system is a system that activates itself without the need of mechanical or electrical actuation. The passive systems are divided into four main categories (A to D), depending on the particular phenomena/device that is not used for the activation of the structure [3]:

1. No moving working fluid,

2. No moving mechanical part,

3. No input signal of "intelligence",

4. No external power input or forces.

${ }_{20}$ For instance, the fuel cladding belongs to the category A (1, 2, 3 and 4 and the pressurizer surge line or the hydraulic diode - one-way flow reduction through vortex effect - to the category B (2, 3 and 4). The accumulators belong to the category C (3) and 4 ) and the SCRAM to the category D (4 only).

The interest of these particular systems is given by the possibilities that derive from their employment. Some of the main benefits are: the simplification of the pipe networks for the safety injection (SI) systems, the potential disappearance of some active elements such as some specific pumps and the economical saving (less active systems to be placed and operated). 


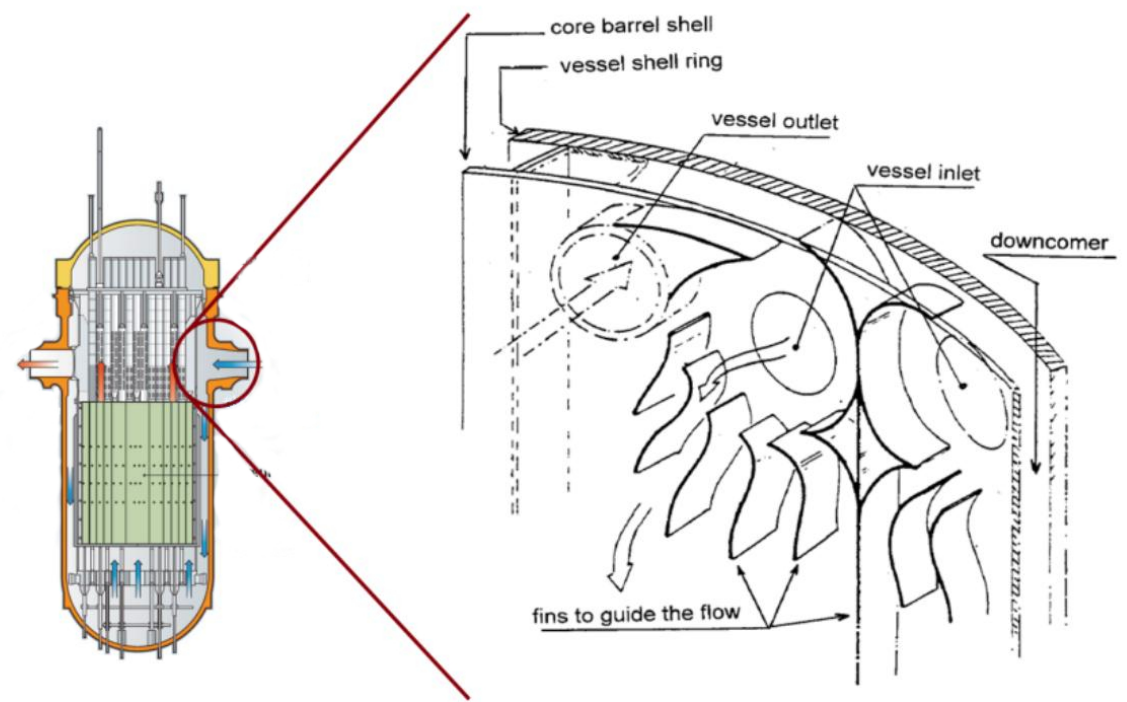

Figure 1: Scheme of in-vessel flow limiters (hydraulic diode) located between the cold legs and the downcomer 4 .

At CEA, some studies on passive safety systems have been done in the past years, notably for the in-vessel flow limiter (hydraulic diode) patented by the CEA [5] designed to limit the amount of water lost during the short-term sequence of a Large-Break (LB) Loss Of Coolant Accident (LOCA), cf. Fig. 1 . French 900 MWe CP1 and 1,300 MWe P4 PWRs and low-pressure PWRs have been the reference reactors for these investigations [4. An other example is the advanced accumulator with passive hydraulic-diode device considered in the Generation III projects (ATMEA1, AP1000, APR1400 , ...) [6, 7]. The goal of this device is to set up a two-step injection regime. The first one is a high-rate injection of the amount of water needed to fill the vessel lower plenum 40 and down-comer. Then, the second step is a low-rate injection limited to just maintain the water level. The expected goal is a better use of the water injected by the SI accumulators and a bigger delay for the on-set of the SI pumps. Let us notice that it is important to assess the conjoint effect of these kind of passive devices. In fact, the effect of an elementary device can be increased 
or minimized in conjunction with other ones. For instance, In-vessel flow limiters and advanced accumulators contribute to strongly reduce the short-term primary-mass lost during LB-LOCA as demonstrated in [8] on a generic 3-loop middle-range electrical-power reactor of 1150 MWe, taking inspiration from the ATMEA1 reactor. In reference to the case without hydraulic diodes, the accumulator injection time is more than doubled (which means that the pumps can start with a bigger delay), the reflooding level is increased of almost $+35 \%$ and the peak cladding temperatures are reduced of about $-10 \%$ and $-43 \%$ on the short and long term. These computations were done with the French reference thermal-hydraulic system safety code CATHARE [9, 10, originally devoted to the study of water-cooled reactor transients (standard operations or accidental transients from any kind of failures or size and location of breaks), that is based on $0 \mathrm{D} / 1 \mathrm{D}$ and 3D modules using six-equation (mass, momentum and energy) two-fluid models. But, the relevance of these system-scale studies depends on the level of realism of the data introduced to model the hydraulic diodes.

60

In order to take into account the large-scale effect of hydraulic diodes in safety-system studies, we need information coming from small-scale experimental or numerical experiments. For instance, results from 3D Computational Fluid Dynamic (CFD) simulations can be used to up-scale relevant character65 istics as the global pressure drop induced by the hydraulic diode. With this information, it is possible to model the effect of an in-vessel flow limiter through the definition of the pressure-drop coefficient in a 1D CATHARE model. This approach is already classic in this context, cf. document 11] for CFD codes in the nuclear reactor safety problems. Moreover, CFD studies can be involved in the optimization process of the flowlimiter geometry to maximize the global pressure drop during a cold-leg LBLOCA. The value of the global pressure-drop coefficient is linked to the geometry of the fins, cf. Fig. 1. The optimization process consists to design a fin geometry minimizing (respectively, maximizing) as much as possible the pres75 sure drop during nominal operations (respectively, a cold-leg LB-LOCA). As 
many geometric scales are presented at the same time (typically several meters for the downcomer radial scale and one centimeter for the fin thickness), a CFD simulation of the two-phase flow inside the flow-limiter can be time consuming. It is incompatible with a big number of simulations needed to optimize the design. Instead of this conventional approach (i.e. body-fitted approach), we are motivated by fictitious domain approach [12, 13, allowing a less precise but faster estimation of the pressure-drop coefficient. Following this way, we consider simulations over a full computational domain including the in-vessel flow-limiter fins and re-introduce their presence adding local external forces on the immersed boundaries. Moreover, a homogeneous relaxed equilibrium model of a liquid-vapour mixture [14] can be considered. For same space discretization, this kind of three-balance-equation model generally run faster than a six-balance-equation model. Once a particular geometry exhibited as a good candidate, a reduced number of body-fitted CFD computations can be done to refine the design.

The aim of this paper is to present a methodology concerning the design of a fast-running two-phase CFD model of the in-vessel flow-limiter device and the 3D/1D up-scaling of these CFD results in order to provide some useful input 95 data in 1D thermal-hydraulic system safety code. The numerical/experimental validation of this simulation tool is not the goal of this paper and only brief elements of validation are given here. In the future, a full validation will be issued based on an improved numerical scheme including, in particular, a second-order in space interpolation scheme across the Immersed Boundary (IB) [15] and an IB-condition consistent fractional-step method [16].

This paper is structured as follow. The two-phase fluid CFD model and the first-order in space immersed boundary models are first presented in Sections 2 and 3 Then, the conditions of the in-vessel flow limiter study are precised in 105 Section 4 with the GENEPI code as CFD tool. The process concerning the $3 \mathrm{D} / 1 \mathrm{D}$ up-scaling of the global pressure-drop coefficient is described in 5 . Re- 
sults are given in Section 6 providing a range of values that may be used in input of safety-system codes and allowing us to compare with the pressure-drop coefficient values used in CATHARE studies 8 .

Finally, we give some words concerning the perspectives of this work in Section 7 and draws some perspectives about future work concerning passive safety systems and expected gains allowed by their introduction.

\section{The two-phase CFD model}

The considered two-phase CFD model is the GENEPI one [17, 18, designed for the steam-generator two-phase flow steady-state 3D computations through the resolution of three balance equations for a water liquid/steam mixture. It is based on a homogeneous relaxed equilibrium model with thermodynamic equilibrium of the two phases. But closure laws take into account the liquid/steam momentum disequilibrium. This code incorporates the possibility to model thin no-penetration obstacles using Immersed Boundary Conditions (IBCs) [19].

After averaging the local and instantaneous mass, momentum and energy equations for each phase, these are merged to obtain a mixture description of the two-phase flow. Provided that the following assumptions hold: (i) surface tension, viscous and turbulent dissipation are neglected and pressure terms are neglected in the enthalpy balance equation, (ii) same pressure for steam and liquid, (iii) eddy viscosity model, one obtains for two-phase flows the following mass and momentum balance equations:

$$
\begin{aligned}
\boldsymbol{\nabla} \cdot \mathbf{G} & =0, \\
\rho \partial_{t} \mathbf{V}+\mathbf{G} \cdot \overline{\bar{\nabla}} \mathbf{V}+\overline{\bar{\nabla}} \cdot\left(x(1-x) \rho \mathbf{V}_{R} \otimes \mathbf{V}_{R}\right) & =\rho \mathbf{g}-\boldsymbol{\nabla} P-\overline{\bar{\Lambda}} \mathbf{V} \\
& +\overline{\bar{\nabla}} \cdot \mu_{T}\left(\overline{\bar{\nabla}} \mathbf{V}+\overline{\bar{\nabla}}^{T} \mathbf{V}\right), \\
\rho \partial_{t} H+\mathbf{G} \cdot \nabla H+\nabla \cdot\left(x(1-x) \rho L \mathbf{V}_{R}\right) & =\boldsymbol{\nabla} \cdot\left(\chi_{T} \boldsymbol{\nabla} H\right),
\end{aligned}
$$

with $\mu_{T}$ the turbulent dynamic viscosity, $\chi_{T}$ the turbulent diffusion coefficient, $\overline{\bar{\Lambda}}$ the singular-obstacle tensor and $\mathbf{V}_{R}$ the relative velocity given by the driftflux Lellouche-Zolotar model [20] and based on the Zuber-Findlay approach [21. 
The density $\rho$, the static quality $x$ and the latent heat $L$ are determined through the equation of state of the water as a function of the pressure and mixture specific enthalpy. We solve in $H, P$ and $\mathbf{V}$ variables. The time term presence in Eq. (2) allows to search the steady-state regime through a transient computation of a thermally dilatable fluid, $\boldsymbol{\nabla} \cdot \mathbf{G}=0$, cf. Eq. (1). For that, the ChorinGresho method 22] (a fractional-step method) is used to solve the coupled mass-momentum equations. The non linearity are dealt by the Picard iterative process. The time discretization is based on a semi-implicit Crank-Nicholson scheme. The spatial discretization is based on the unstructured hexahedral finite elements (constant pressure by element and tri-linear velocity by node). The physical data $\rho, \mu_{T}$ and $\overline{\bar{\Lambda}}$ are constant by element. The Streamline Upwind Petrov-Galerkin (SUPG) method is applied to correct the convective term [23]. A conjugated gradient method, preconditioned by the diagonal, is used to solve the arising linear systems.

In GENEPI, the turbulence modeling is done thank to a very simple local scalar model, the Schlichting model [24]:

$$
\mu_{T}=a_{S}|\mathbf{G}| L_{T}
$$

where $L_{T}$ is a characteristic length and $a_{S}$ a coefficient. This turbulence model is known to be quite diffusive. The turbulent diffusion coefficient $\chi_{T}$ for the enthalpy balance equation is defined via the Prandtl number $P_{r}=\frac{\mu_{T}}{\chi_{T}}$.

According to the hyperbolic nature of the flow equations, Dirichlet boundary conditions are used at the inlets of the domain (mass flux and enthalpy) and Neumann boundary conditions at the outlets (pressure). The other boundaries of the domain are impermeable walls. Generally, these are considered adiabatic and with no shear stress.

\section{The Immersed Boundary Model}

In the fictitious domain approach, introduced in the fifties by Hyman 25] and the Russian's school [12, 13, the original domain $\tilde{\Omega}$ is embedded in a fictitious domain $\Omega$ which is geometrically bigger and generally simpler-shaped. 


\subsection{The ISI method}

In this work, among the numerous fictitious domain methods (see [19] for a short introduction), we consider an element of the set of Immersed Boundary Methods: the fictitious domain method with Immersed Spread Interface (ISI) [26, 19]. The fictitious problem to be solved in $\Omega$ is built from the original problem in $\tilde{\Omega}$, but an additional term takes into account the immersed boundary conditions. For velocity Dirichlet boundary conditions, the singular-obstacle tensor $\overline{\bar{\Lambda}}$ of Eq. 22 will play this role. It allows us to take into account the nopenetration condition of the flow limiter fins in an implicit way during the first step of the Chorin-Gresho method.

Let us $(\mathbf{u}, \mathbf{v}, \mathbf{w})$ be the local basis linked to a given obstacle (i.e. fin). The vectors $\mathbf{u}$ and $\mathbf{v}$ are tangential to the obstacle and the vector $\mathbf{w}$ is normal to the obstacle. For the element $e$, we define the singular-obstacle tensor by:

$$
\overline{\bar{\Lambda}}_{e}=\rho_{e} \frac{A_{e}}{\Omega_{e}}\left(\begin{array}{ccc}
\Lambda_{u} & 0 & 0 \\
0 & \Lambda_{v} & 0 \\
0 & 0 & \Lambda_{w}
\end{array}\right)
$$

with $A_{e}$ the measure of this obstacle (area, $m^{2}$ ) intercepted by the element $e$ and $\Omega_{e}$ the measure (volume; $m^{3}$ ) of this element. $\Lambda_{u}, \Lambda_{v}$ and $\Lambda_{w}$ are the tensor coefficients in, respectively, the directions $\mathbf{u}, \mathbf{v}$ and $\mathbf{w}$. Here, we consider no-penetration obstacles in the normal direction, $\Lambda_{w}=1 / \epsilon$ with $0<\epsilon<<1$, and slip conditions in the tangential directions, $\Lambda_{u}=\Lambda_{v}=0$.

Immersed interfaces $\Sigma$, as the flow-limiter fins, are modeled by a collection of linear plane surfaces intercepting elements of $\Omega$. In each intercepted element, the 
measure of the intercepted surface and the external normal vector are known. As the singular-obstacle tensor is defined by element, all the nodes belonging to this element are concerned: i.e. we have a spread interface approximation of $\Sigma$.

\subsection{Convergence order and elements of validation}

As for the $L^{2}$-penalty methods [12, 27, that the ISI method generalizes, the parameter $\epsilon$ is known as the penalty parameter. Regardless to the Navier-Stokes solving method, the theoretical rate of convergence of the penalized solution toward the body-fitted one is comprised in the range $\left[\mathcal{O}\left(\epsilon^{1 / 4}\right) ; \mathcal{O}\left(\epsilon^{1}\right)\right]$ in $L^{2}(\Omega)$ norm [27. Let us notice that for Dirichlet boundary conditions and elliptic problems, the theoretical rate of convergence in space of the $\mathcal{Q}_{1}$-finite element method with non-boundary-fitted meshes is $\mathcal{O}\left(h^{1}\right)$ in $L^{2}(\Omega)$ norm, with $h$ the space step [28].

As a whole, contributions to the validation of this IB approach can be found in [19] and [15. On one side, in the context of dilatable two-phase flow elliptic problems, the work mentioned in [19] validates the ISI method with respect to body-fitted finite-element computations and to the JEBC method (an IB method using a finite-volume discretization). A first-order rate of convergence in space is numerically reached.

On the other side, in the context of incompressible one-phase flow Navier-Stokes equation, the work mentioned in [15] gives elements of validation for a finitevolume first-order penalty method very similar to the ISI method. Again, a first-order rate of convergence in space is numerically reached on the test case of a laminar flow around a static cylinder of diameter $D$ (Reynolds number $=20$ ). These results are in very good agreement with those proposed in the literature, cf. Table 1. In a lesser degree, it is also true for our own GENEPI results using the ISI method (about $10 \%$ on the drag coefficient and $30 \%$ on the recirculation length) giving confidence in the ability to catch the magnitude of an obstacle's drag coefficient. 


\begin{tabular}{|c|c|c|c|c|c|c|c|c|c|}
\hline \multirow{2}{*}{} & \multicolumn{2}{|c|}{ GENEPI } & \multicolumn{7}{|c|}{ References } \\
\cline { 2 - 10 } & B.F. & ISI & {$[15]$ (base) } & {$[29$} & {$[30$} & {$[31]$} & {$[32]$} & {$[33$} & {$[34]$} \\
\hline$C_{d}$ & 2.13 & 2.30 & 2.06 & 2.03 & 2.02 & 2.06 & 2.06 & 2.00 & 2.09 \\
\hline$\frac{L_{w}}{D}$ & 0.96 & 1.22 & 0.93 & 0.92 & 0.9 & 0.94 & 0.93 & 0.91 & - \\
\hline
\end{tabular}

Table 1: Hydrodynamic coefficients associated with the problem of steady flow around a static cylinder of diameter $D$ (Reynolds number 20). B.F.: Body-fitted. $C_{d}$ : drag coefficient. $L_{w}$ : recirculation length. [15] (base) refers to the first-order penalty method of [15]. ISI: 18 cells in the diameter $D$ and $\epsilon=10^{-5}$.

\section{CFD studies of the in-vessel flow limiter}

With the CATHARE code, even it allows coarse 3D meshing, it is not possible to run simulations including the effective geometry of the fins and the 
$0.4 m^{2}$ respectively.

For the purpose of a mesh convergence study, three meshes $M_{1}, M_{2}$ and $M_{3}$ were built involving $N_{1}=6,080, N_{2}=48,640$ and $N_{3}=164,160$ elements respectively. Each mesh $i$ can be characterized by a space-step index $i d_{i}=1 / \sqrt[3]{N_{i}}$ defining a mean space step $h_{i}=i d_{i} V(\Omega)$ with $V(\Omega)$ the computational domain volume $\left(3.8 \mathrm{~m}^{3}\right)$. The mean space step ranges from $0.2 \mathrm{~m}\left(M_{1}\right)$ to $0.07 \mathrm{~m}\left(M_{3}\right)$ and the ratio between two consecutive space-step indexes is $2.0\left(M_{1} \rightarrow M_{2}\right)$ and $1.5\left(M_{2} \rightarrow M_{3}\right)$.

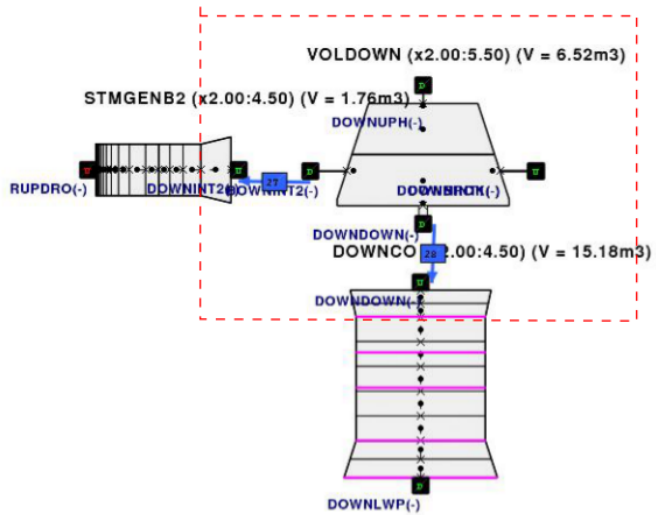

Figure 2: Part of the PWR geometry taken into account by the CFD study of the in-vessel flow limiter.

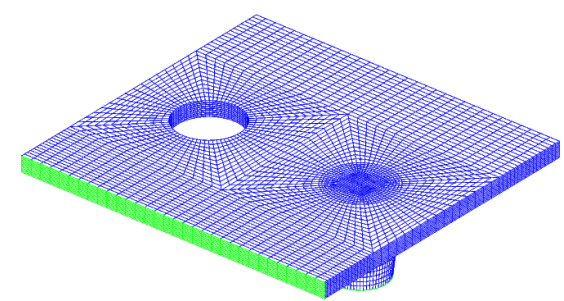

(a) Down-comer surface (green).

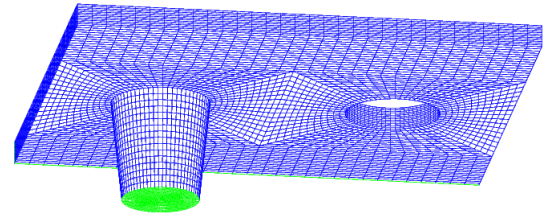

(b) Cold-leg nozzle surface (green).

Figure 3: Example of the mesh used for the CFD study of the in-vessel flow limiter (mesh $M_{2} ; 48640$ elements). The walls are colored in blue.

We have set-up a preliminary design of the in-vessel flow limiter. The flow- 
limiter fins are modeled by singular-obstacle surfaces through a collection of plane surfaces, cf. Fig. 4

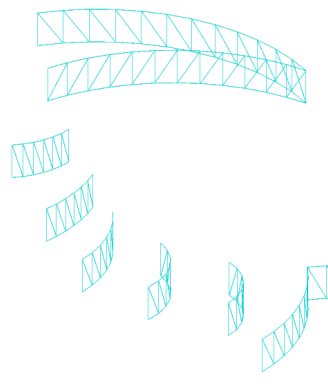

(a) Flow limiter meshing.

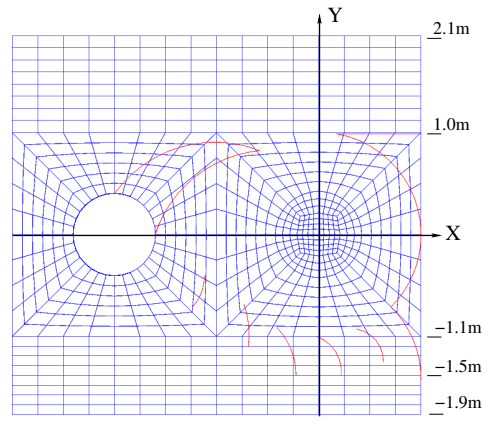

(b) Singular obstacles positioned in the computational domain (mesh $M_{1}$; 6,080 elements).

Figure 4: Example of preliminary meshing of the flow limiter.

\subsection{Boundary conditions}

Mass flux $Q_{i n}$ is imposed on the in-flow boundary and ad-hoc pressure $P_{\text {out }}=50$ bar on the out-flow boundary. The in-flow and out-flow surfaces are the down-comer and the cold-leg nozzle surfaces depending on the considered main-flow direction (default, as in nominal-operation condition, or reverse, as in LB-LOCA condition). Slip-wall boundary conditions are considered on the walls.

The inlet mass fluxes are given by the steady-state CATHARE computation for the default flow direction and by CATHARE transient results at time $t=10 \mathrm{~s}$ after the guillotine break opening for reverse flow direction. For the reverse flow direction case, this instant is chosen so that the equations of state of GENEPI and CATHARE are compatible (primary pressure in the range [40-60] bar). At this time, CATHARE provides the pressure value of 64.6 bar. The inlet mass-flux values $Q_{i n}$ are

- Nominal-operation condition (default flow direction):

$Q_{\text {in }}=4,690 \mathrm{~kg} / \mathrm{s}$, in $\leftrightarrow$ cold leg and out $\leftrightarrow$ downcomer, 
- LB-LOCA condition (reverse flow direction):

$Q_{\text {in }}=5,200 \mathrm{~kg} / \mathrm{s}$, in $\leftrightarrow$ downcomer and out $\leftrightarrow$ cold leg.

\subsection{Computation hypothesis}

For simplicity reason, we do not give attention to the gravitational acceleration term in the GENEPI or CATHARE computations (around the flow limiter, gravitational effects are negligible in comparison with the inertial ones during the fast-depressurization phase). As well, the pressure range considered here is only [40-60] bar. It differs from the pressure addressed in the CATHARE simulations of the nominal operation or of the LB-LOCA. But it is the pressure drop that is important at first, mainly for one-phase flow computations.

240 Concerning the turbulence model, cf. Eq (4), the GENEPI-code standard value for the Schlichting coefficient is $a_{S}=0.047$ and the turbulence characteristic length $L_{T}$ is related to the biggest eddy structures. As reference, we choose $L_{T} \approx 1 m$ for the nominal-operation flow direction (azimuth scale in the downcomer) and $L_{T} \approx 0.3 \mathrm{~m}$ for reverse flow direction toward the broken cold leg $(\approx$ radial scale in the down-comer).

\section{3D/1D up-scaling of the global pressure-drop coefficient}

\subsection{The CATHARE model}

In our CATHARE model, the cold-legs are modeled by three axial elements and the down-comer by a single axial element connected to a volume element, cf. Fig. 2 where only one cold-leg is shown. On this volume are defined the local pressure-drop coefficients for the junctions that connect this element to the cold-legs: $K_{i n}$ for fluid flowing into the volume (default flow direction, nominaloperation condition) and $K_{\text {out }}$ for fluid flowing out (reverse flow).

CATHARE computations in [8] highlight the benefice brought by a out-flow 255 pressure-drop coefficient $K_{\text {out }}$ equals to 11.7 , corresponding to a multiplying factor $K=15$ of the initial pressure-drop coefficient. The motivation of this $3 \mathrm{D} / 1 \mathrm{D}$ up-scaling approach is to answer to the question: is this value realistic ? 


\subsection{Methodology}

Let us recall that the CFD computational domain is based on the CATHARE space discretization. To compare the CATHARE results to the CFD ones, we do not directly compare the value of the CATHARE local pressure-drop coefficients $K_{\text {out }}$ to a CFD estimation. But we consider the global pressure-drop coefficients $K_{g l}$ computed between the in-flow/out-flow section of the CFD computational domain marked in red in Fig. 2 .

Taking as reference the normal mixture mass-flux at the beginning of the coldleg nozzle, $\mathbf{G}_{\mathbf{c l}} \cdot \mathbf{n}_{\mathbf{c l}}=\rho_{\mathbf{c l}} \mathbf{V}_{\mathbf{c l}} \cdot \mathbf{n}_{\mathbf{c l}}$, we define $K_{g l}$ as:

$$
K_{\text {gl }}=2 \frac{<P_{\text {in }}>-<P_{\text {out }}>}{<\rho_{c l}><\left|\mathbf{V}_{\mathbf{c l}} \cdot \mathbf{n}_{\mathbf{c l}}\right|>^{\mathbf{2}}}
$$

where the symbol $\langle\cdot\rangle$ denotes an area average and $\mathbf{n}_{\mathbf{c l}}$ the surface normal. A positive value of $K_{g l}$ denotes a pressure loss: $\left.\left\langle P_{\text {out }}\right\rangle \leq<P_{\text {in }}\right\rangle$. From a discrete-space point of view, considering the three meshes $M i=M_{1} \ldots M_{3}$, we denote by $K_{M i}$ the computed approximations of $K_{g l}$. Let's emphasize that the variables in Eq. (6) are defined for a liquid/steam mixture.

Similarly to the CFD global pressure-drop coefficient $K_{g l}$, we can define a global pressure-drop coefficient for the CATHARE computation $K_{g l, c a t h}$ :

$$
K_{\text {gl,cath }}=2 \frac{P_{\text {in }}-P_{\text {out }}}{\rho_{\text {cl }} V_{c l}^{2}} .
$$

Here the density $\rho_{c l}$ is computed using an upstream approximation and the pressures $P_{\text {in }}$ and $P_{\text {out }}$ using a downstream approximation. Obviously, the global pressure-drop coefficient $K_{g l}$ is linked to the local pressure-drop coefficients $K_{i n}$ and $K_{\text {out }}$ of the down-comer volume element.

Let us notice that the global pressure-drop coefficient can be coarsely estimated using macroscopic analytic expressions, as Borda-Carnot law [35], or experimental correlations, as Idel'cik [36]. The Borda-Carnot law defines the irreversible losses for incompressible flows through head loss coefficient $0<\xi$ : $E_{1}=E_{2}+\xi / 2 \rho\left(V_{1}-V_{2}\right)^{2}$ with the head defined as $0<E=P+1 / 2 \rho V^{2}$ and location 2 downstream to location 1 . 


\section{Results}

270 performed on the coefficient $a_{S}$ and the turbulence characteristic length $L_{T}$, cf. Eq (4): $a_{S} \in\{\mathrm{a}=0.047, \mathrm{a} / 10\}$ and $L_{T} \in\{0.3,1.0,2.0\}$. The value of the penalty parameter is set to $\epsilon=10^{-5}$.

We consider that the GENEPI steady state is reached when the relative $L^{2}$-norm

Although the mesh convergence is not fully reached, the trend of the evolution of the pressure-drop coefficient versus the space-step index is globally caught. 


\begin{tabular}{|c|c|c|c|c|c|c|c|}
\hline & & \multicolumn{3}{|c|}{$\begin{array}{l}\text { Without } \\
\text { limiter }\end{array}$} & \multicolumn{3}{|c|}{$\begin{array}{l}\text { With } \\
\text { limiter }\end{array}$} \\
\hline $\begin{array}{c}\text { Flow } \\
\text { direction }\end{array}$ & Turbulence & $K_{M 1}$ & $K_{M 2}$ & $K_{M 3}$ & $K_{M 1}$ & $K_{M 2}$ & $K_{M 3}$ \\
\hline Default & $\begin{array}{c}\mathrm{a} ; L_{T}=2 \mathrm{~m} \\
\mathrm{a} / 10 ; L_{T}=2 \mathrm{~m} \\
\mathrm{a} / 10 ; L_{T}=0.3 \mathrm{~m} \\
\mathrm{a} ; L_{T}=\mathbf{0 . 3} \mathrm{m} \\
\mathrm{a} ; L_{T}=1.0 \mathrm{~m}\end{array}$ & $\begin{array}{c}2.5 \\
0.4 \\
0.4^{(*)} \\
0.4 \\
1.2\end{array}$ & $\begin{array}{l}0.3 \\
0.8\end{array}$ & $\begin{array}{c}-0.3 \\
0.1\end{array}$ & $\begin{array}{l}6.2 \\
9.8\end{array}$ & $\begin{array}{l}1.8^{(*)} \\
3.1^{(*)}\end{array}$ & $\begin{array}{c}0.7^{(*)} \\
1.6\end{array}$ \\
\hline \multicolumn{2}{|c|}{ Borda-Carnot $(\xi=1)$} & \multicolumn{3}{|c|}{$K_{g l} \approx-0.5$} & & & \\
\hline Reverse & $\begin{array}{c}\mathrm{a} ; L_{T}=2 \mathrm{~m} \\
\mathrm{a} ; L_{T}=2 \mathrm{~m} ; \mathrm{BTD} \\
\mathrm{a} / 10 ; L_{T}=2 \mathrm{~m} \\
\mathrm{a} ; L_{T}=0.3 \mathrm{~m} \\
\mathrm{a} ; L_{T}=\mathbf{1 . 0} \mathbf{~ m} \\
\text { l'cik } \underline{36} \\
\text { Carnot }(\xi=1)\end{array}$ & $\begin{array}{c}4.6 \\
4.9 \\
4.7^{(*)} \\
4.3^{(*)} \\
3.9\end{array}$ & $\begin{array}{l}4.2 \\
4.2^{(*)} \\
2.7^{(*)} \\
3.7 \\
g l \approx 1 \\
g l \approx 1\end{array}$ & $\begin{array}{l}3.6 \\
3.7\end{array}$ & $\begin{array}{l}13.3 \\
15.9\end{array}$ & $\begin{array}{l}5.3 \\
7.0\end{array}$ & $\begin{array}{l}5.4 \\
6.4\end{array}$ \\
\hline
\end{tabular}

Table 2: Summary of the global pressure-drop coefficients $K_{g l}$. The default flow direction is defined as the nominal-operation flow direction (from the cold leg to the down-comer). The reverse flow direction is defined as the opposite direction. $\left(^{*}\right)$ : unsteady computation. BTD: Balancing Tensor Diffusivity method [37] used instead of the SUPG method.

\subsection{Nominal-operation condition}

For the nominal-operation configuration (fluid flowing toward the downcomer), the pressure and velocity distributions are shown in Figs 5 and 6 with and without flow limiter. The local external-force distribution is illustrated in Fig. $7(\mathrm{a})$. Introducing the flow-limiter device, the regular standard flow path becomes much more irregular with the emergence of flow channels between the fins, cf. Fig. 6(b)] Also, the in/out-flow pressure difference is increased in reference to the case without in-vessel flow limiter: $K_{M 3} \in[-0.3 ;+0.1] \rightarrow$ $[0.7 ; 1.6]$, cf. Fig. $5(\mathrm{~b})$ and Table 2 From a practical point of view concerning 
the implementation of the flow limiter in PWRs, this must be confronted with the primary-pump characteristics to check if this overhead can be offset.

Let us notice that, without flow limiter, the range of $\mathrm{CF}$-computed values $K_{M 3} \in$ $310[-0.3 ;+0.1]$ is compatible with the Idel'cik (output of a rectilinear diffuser on a screen) or Borda-Carnot (sudden flow-section expansion) estimation one $K_{g l} \in$ $[-0.5 ;+0.5]$.

Fig. 8 shows a comparison of the pressure and velocity profiles with and without the flow limiter. The profiles are computed along the line $(0 . \mathrm{m}$, $315[-2.0 ; 2.0] \mathrm{m}, 0.1 \mathrm{~m}$ ), cf. Fig. 4. The pressure drop (about 1 bar) through the flow-limiter fins region, $Y \in[-1.5 ;-1.1] \mathrm{m}$, is clearly visible in Fig. 8(a) as well as the velocity perturbations, cf. Fig. 8(b) As a whole, in the central in-flow region around $Y=0 \mathrm{~m}$, the original velocity profiles and magnitudes are conserved when the flow limiter is added. Let's notice that, in the down-comer, 320 the general direction of the incoming flow from the primary pipe is essentially axial (small velocity $X$-components) with or without the flow limiter.

Fig. 9 shows the mesh convergence concerning the pressure and velocity profiles. The profiles obtained with the $M_{3}\left(164,160\right.$ elements) and $M_{2}(48,640$ 325 elements) meshes are relatively closed in comparison with the profiles obtained with the coarse mesh $M_{1}$ (6,080 elements). Even if the mesh convergence is not completely reached, it gives confidence in the physical tendencies deduced from the fine-mesh result analysis. 


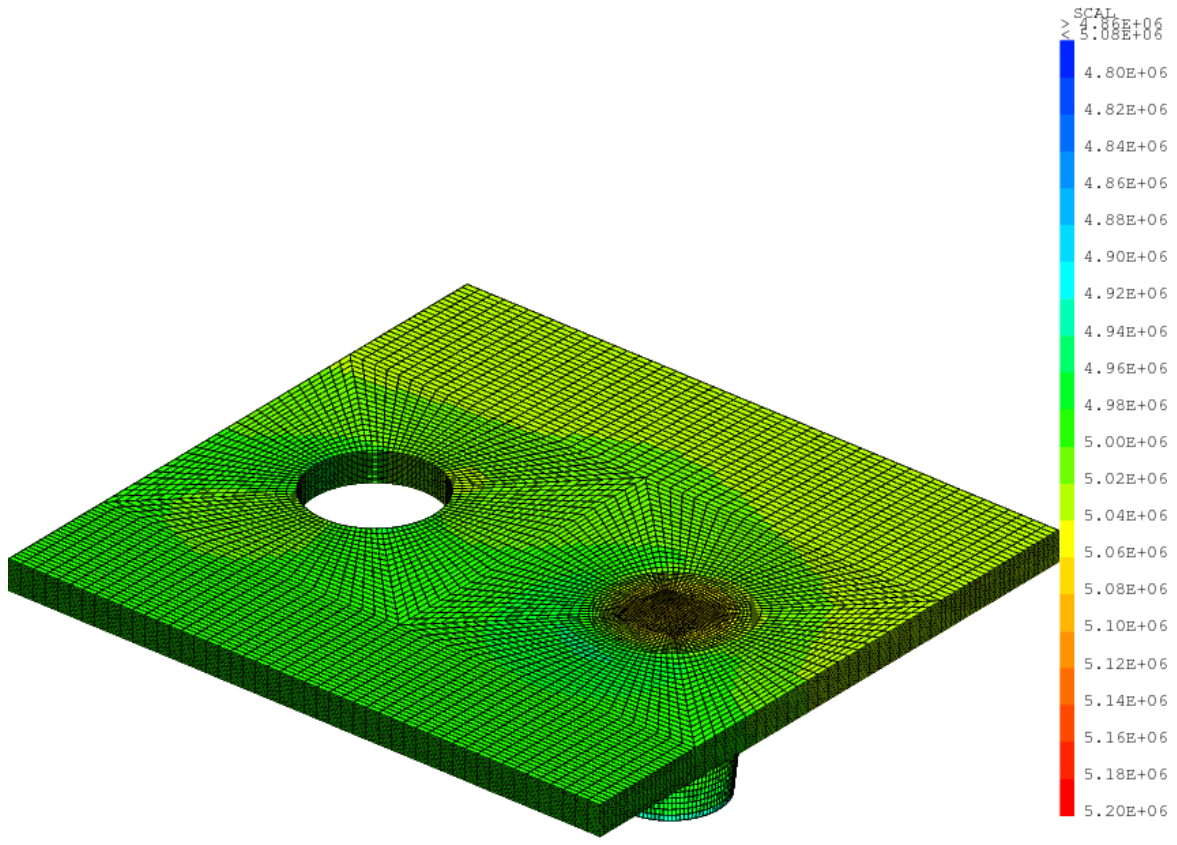

(a) Without flow limiter.

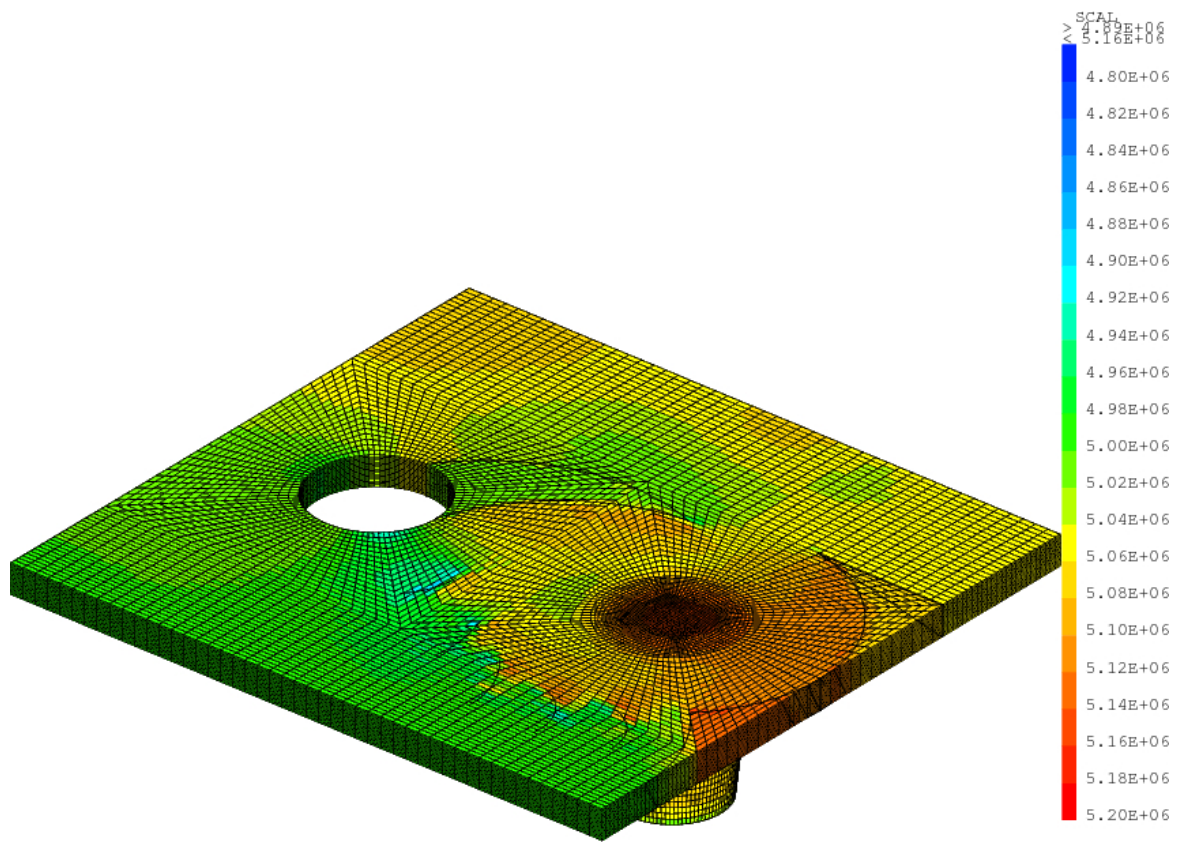

(b) With flow limiter.

Figure 5: Comparison of the pressure in nominal-operation condition; mesh $M_{3}(164,160$ elements); $\left(a_{S}=a ; L_{T}=0.3 \mathrm{~m}\right)$. Pressure iso-values ranges from 4.8 to $5.2 \mathrm{bar}$. 


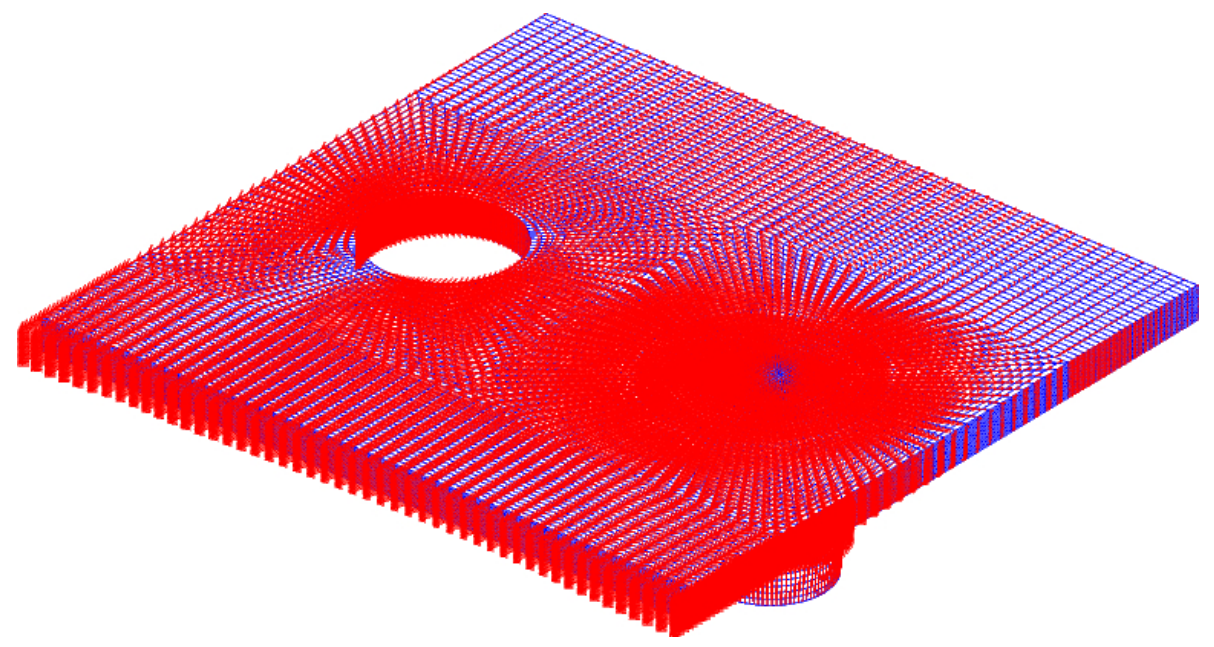

(a) Without flow limiter.

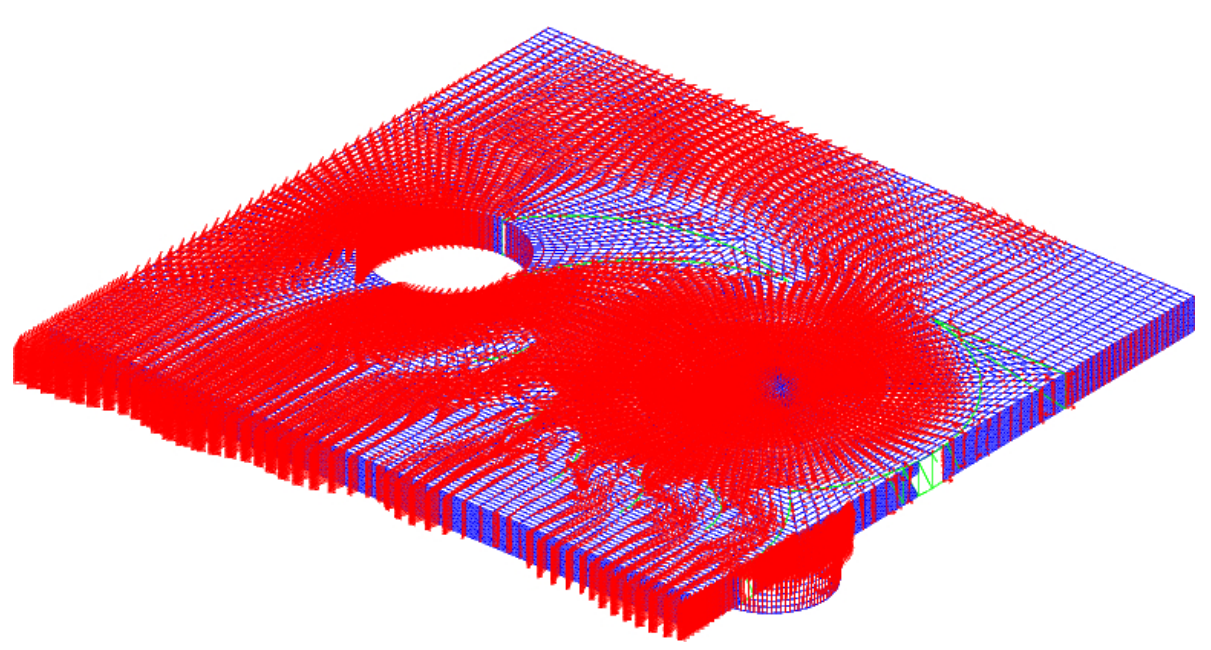

(b) With flow limiter.

Figure 6: Comparison of the velocity in nominal-operation condition; mesh $M_{3}(164,160$ elements); $\left(a_{S}=a ; L_{T}=0.3 \mathrm{~m}\right)$. 


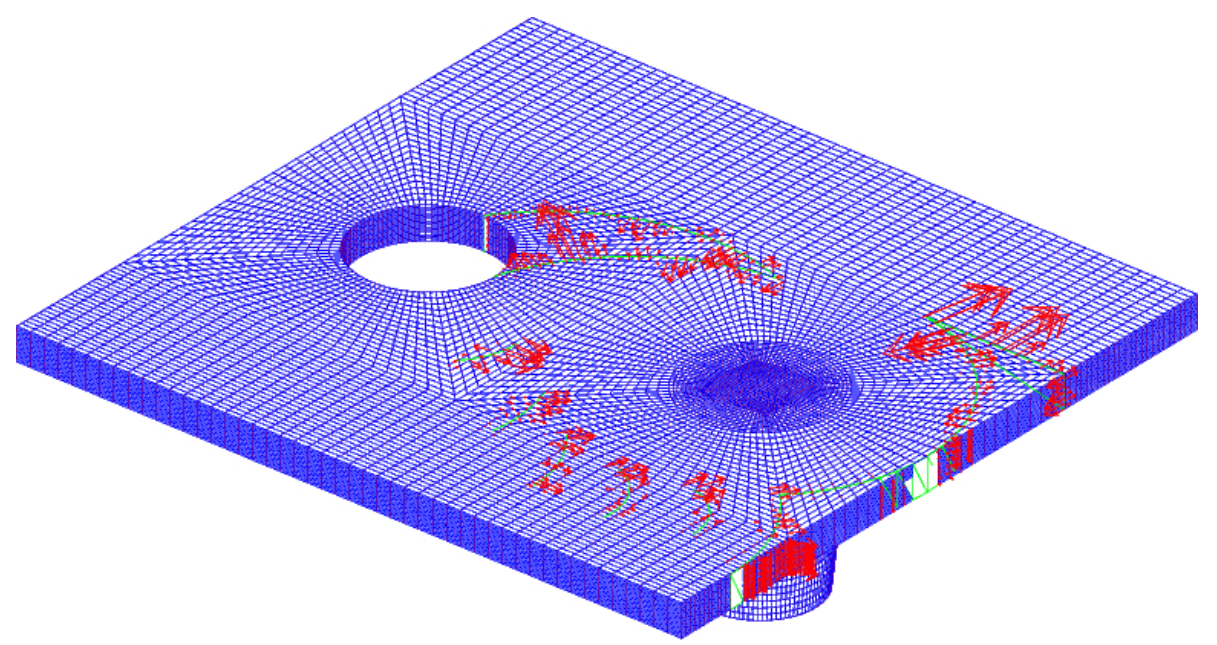

(a) Nominal-operation flow; $\left(a_{S}=a ; L_{T}=0.3 \mathrm{~m}\right)$.

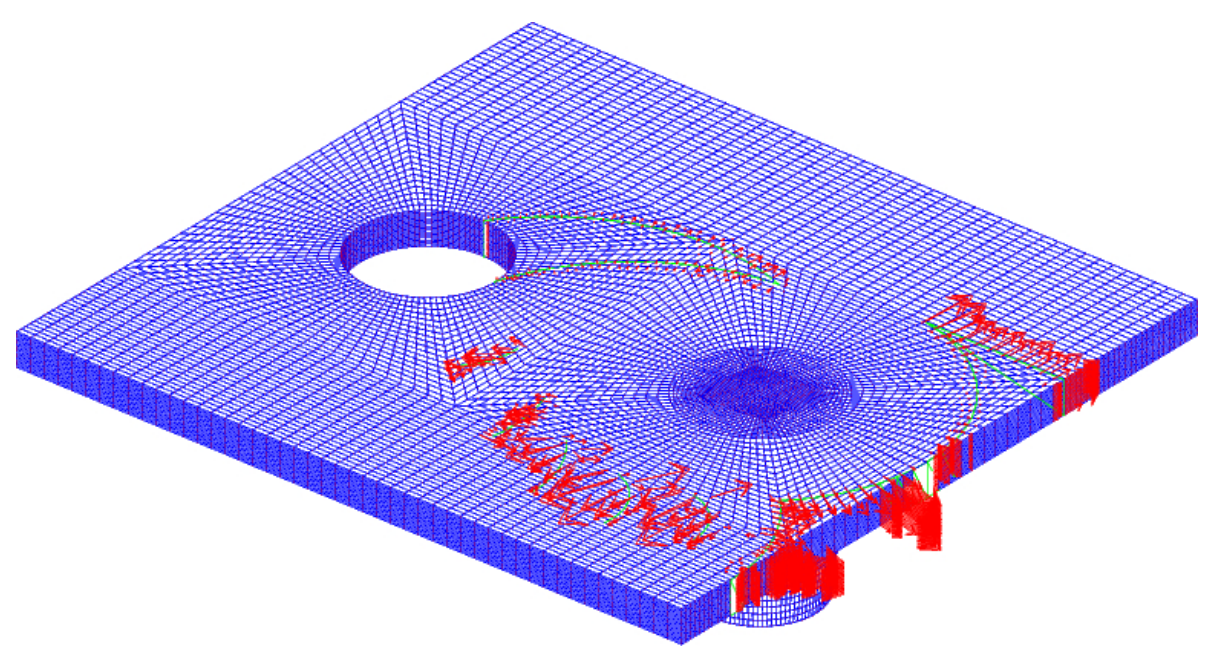

(b) Reverse flow; $\left(a_{S}=a ; L_{T}=1.0 \mathrm{~m}\right)$.

Figure 7: Local external-force distribution; mesh $M_{3}$ (164,160 elements). 


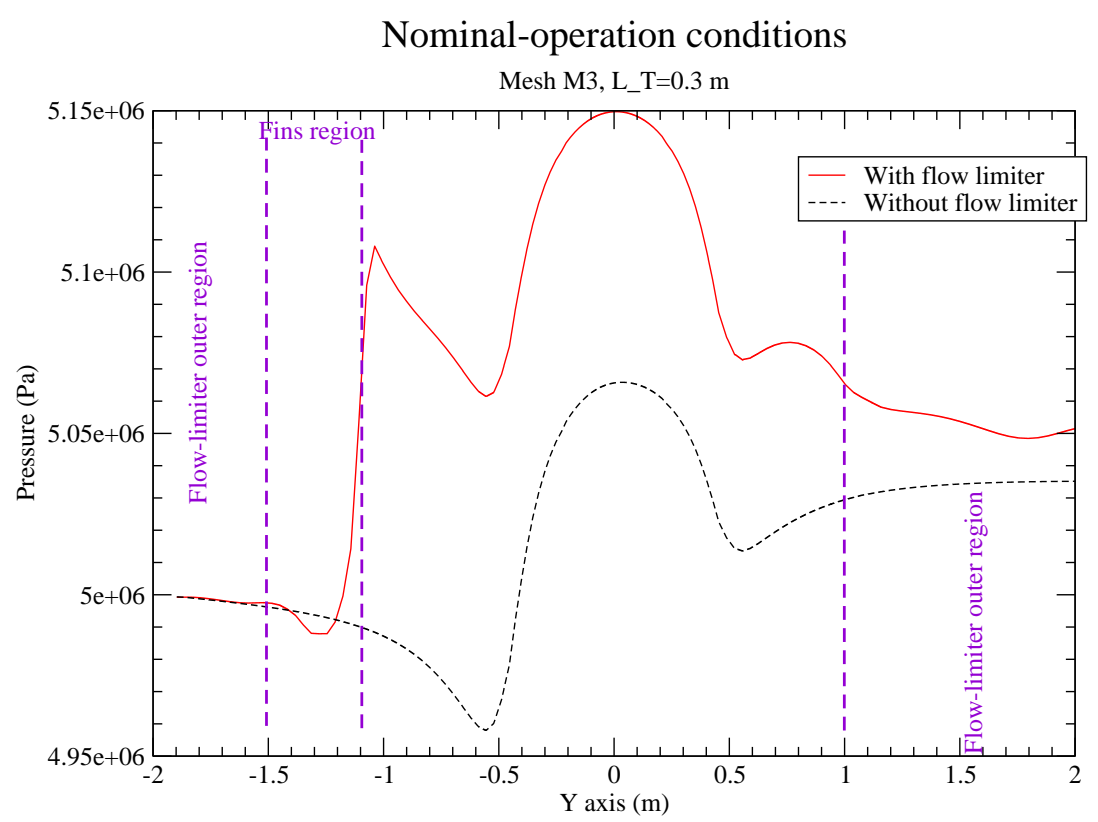

(a) Pressure.

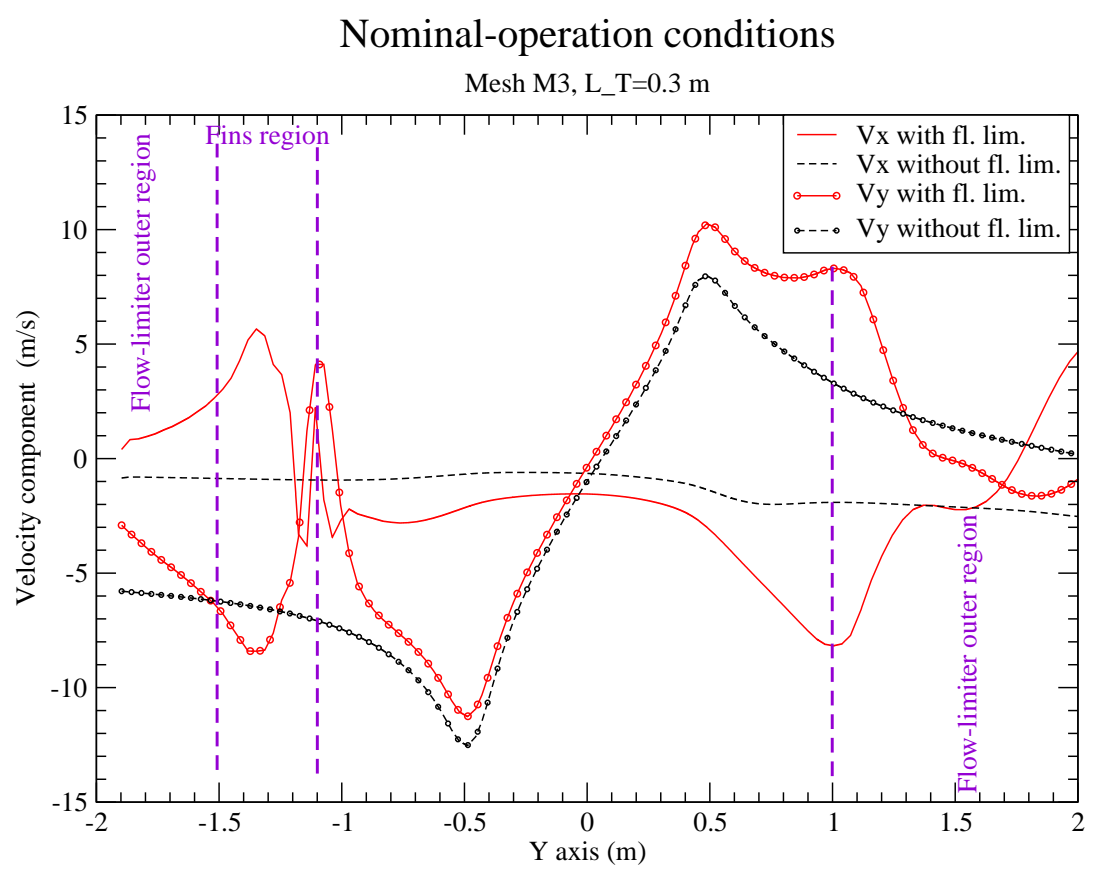

(b) Velocity $X / Y$-components.

Figure 8: Comparison of the pressure and velocity profiles in nominal-operation condition; mesh $M_{3}\left(164,160\right.$ elements); $\left(a_{S}=a ; L_{T}=0.3 \mathrm{~m}\right)$. 


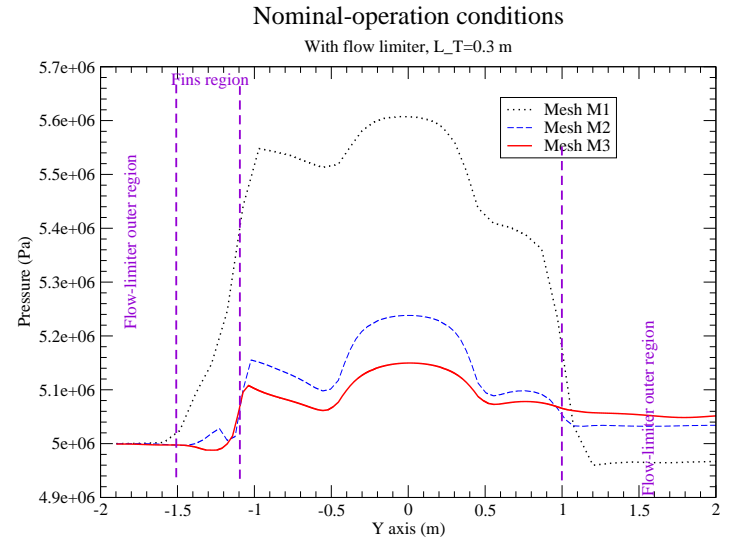

(a) Pressure.

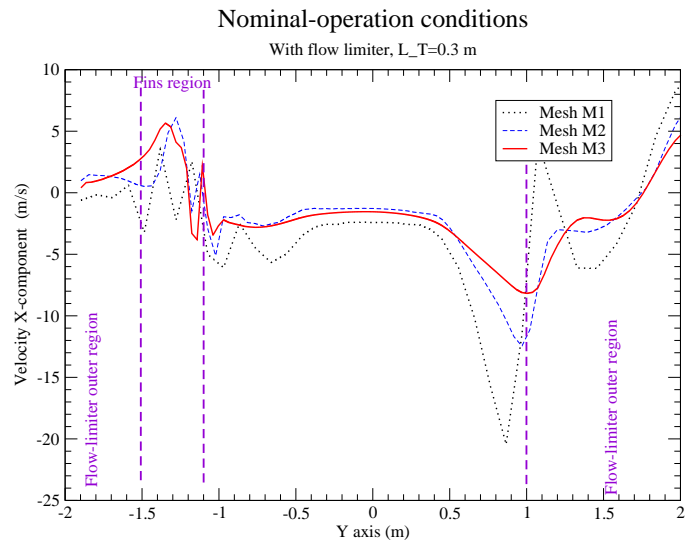

(b) Velocity $X$-component.

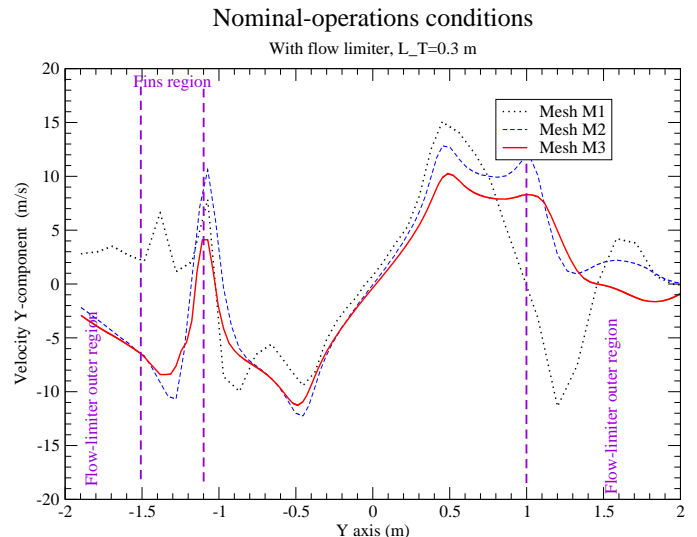

(c) Velocity $Y$-component.

Figure 9: Mesh convergence of the pressure and velocity profiles in nominal-operation condition; $\left(a_{S}=a ; L_{T}=0.3 \mathrm{~m}\right)$. 


\section{2. $L B-L O C A$ condition}

Here again, in the central out-flow region around $Y=0 \mathrm{~m}$, the original profiles and magnitudes of the pressure and the velocity are conserved when the flow limiter is added. Whatever the situation is, there is a vortex of out-coming flow moving toward the primary pipe exit. But with the flow limiter, due to

Fig 12(b), Hence, the flow-limiter induced pressure drop magnitude is relatively high: about 3.5 bar. 


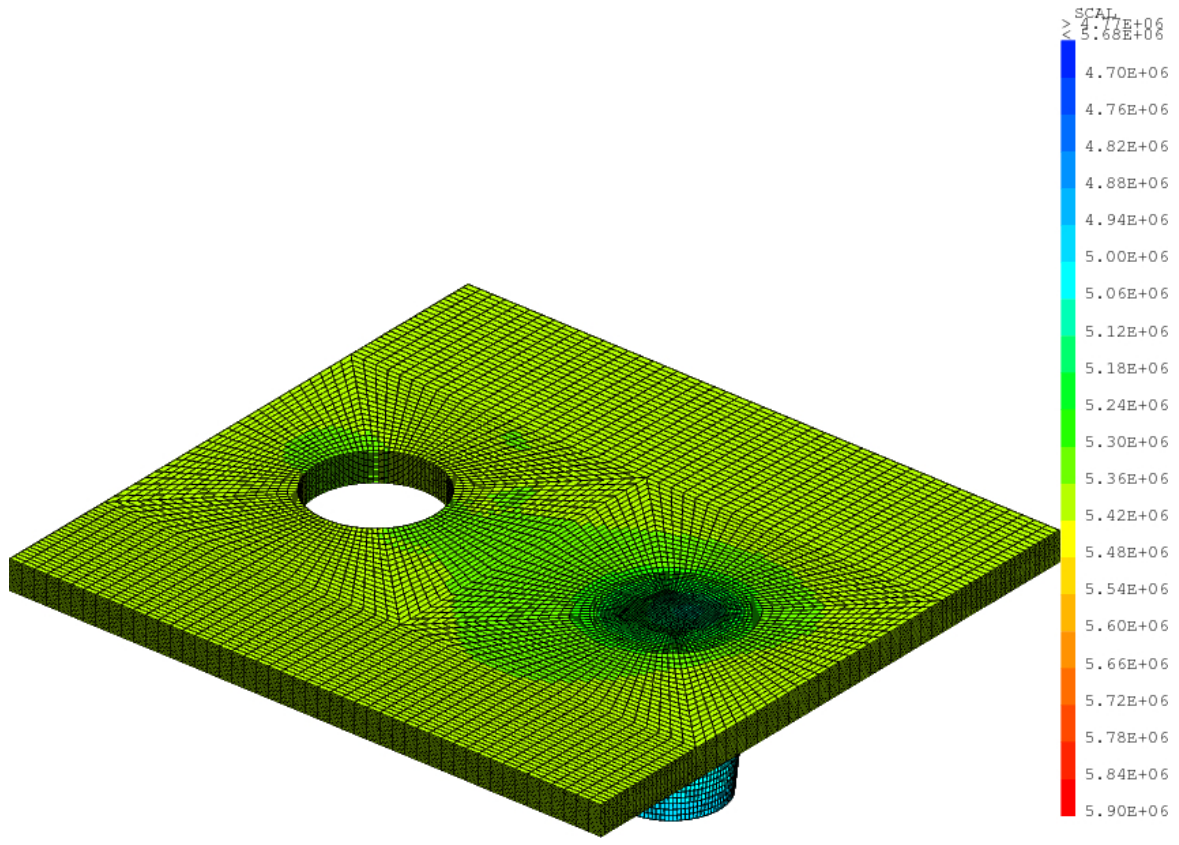

(a) Without flow limiter.

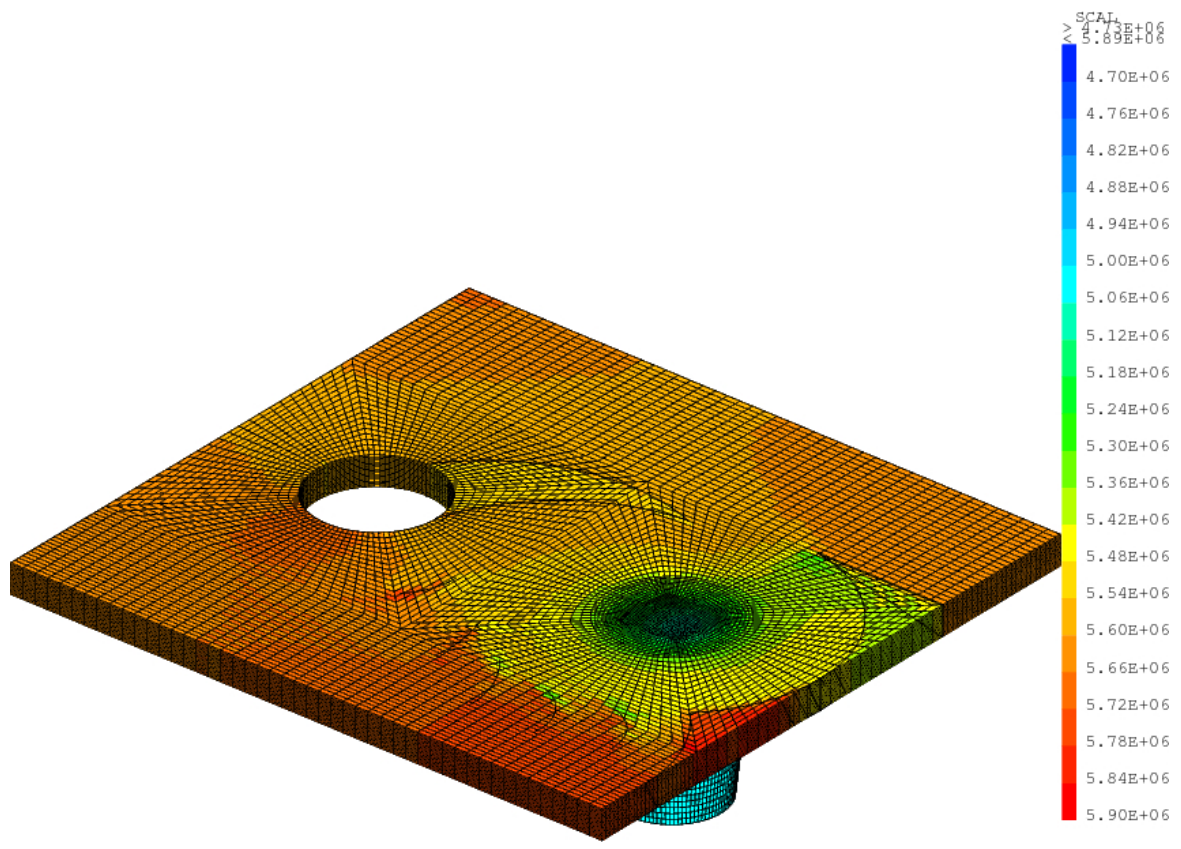

(b) With flow limiter.

Figure 10: Comparison of the pressure in LB-LOCA condition; mesh $M_{3}$ (164,160 elements $) ;\left(a_{S}=a ; L_{T}=1.0 \mathrm{~m}\right)$. Pressure iso-values ranges from 4.7 to $5.9 \mathrm{bar}$. 


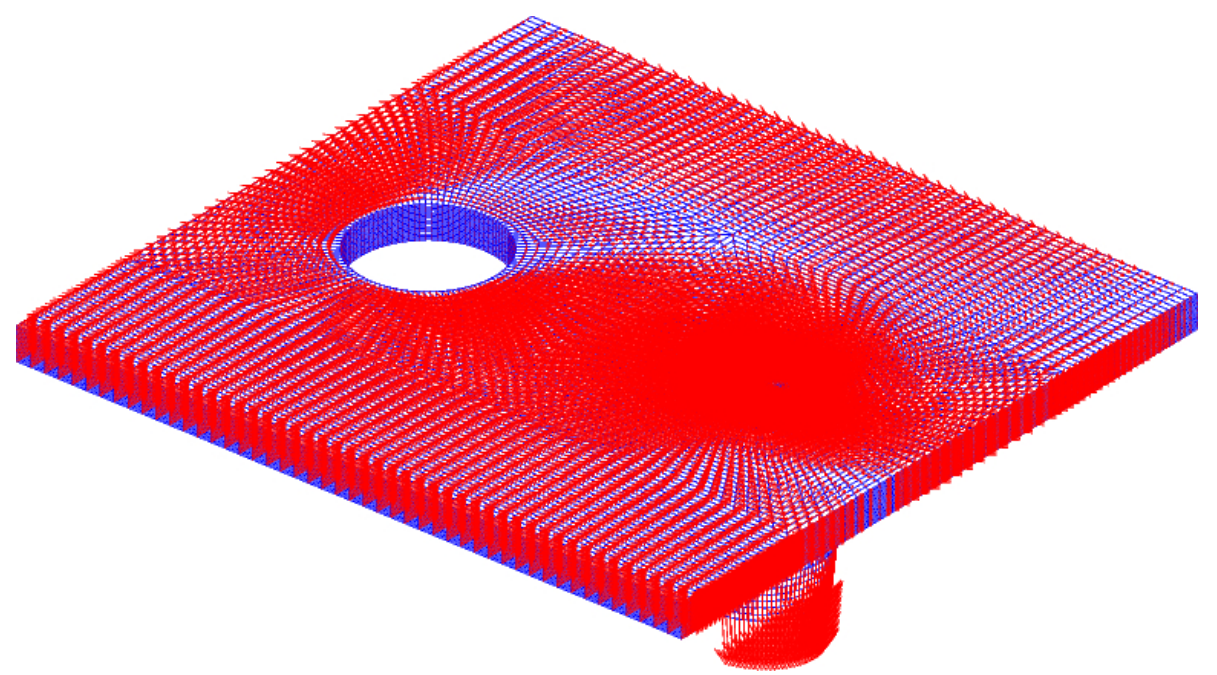

(a) Without flow limiter.

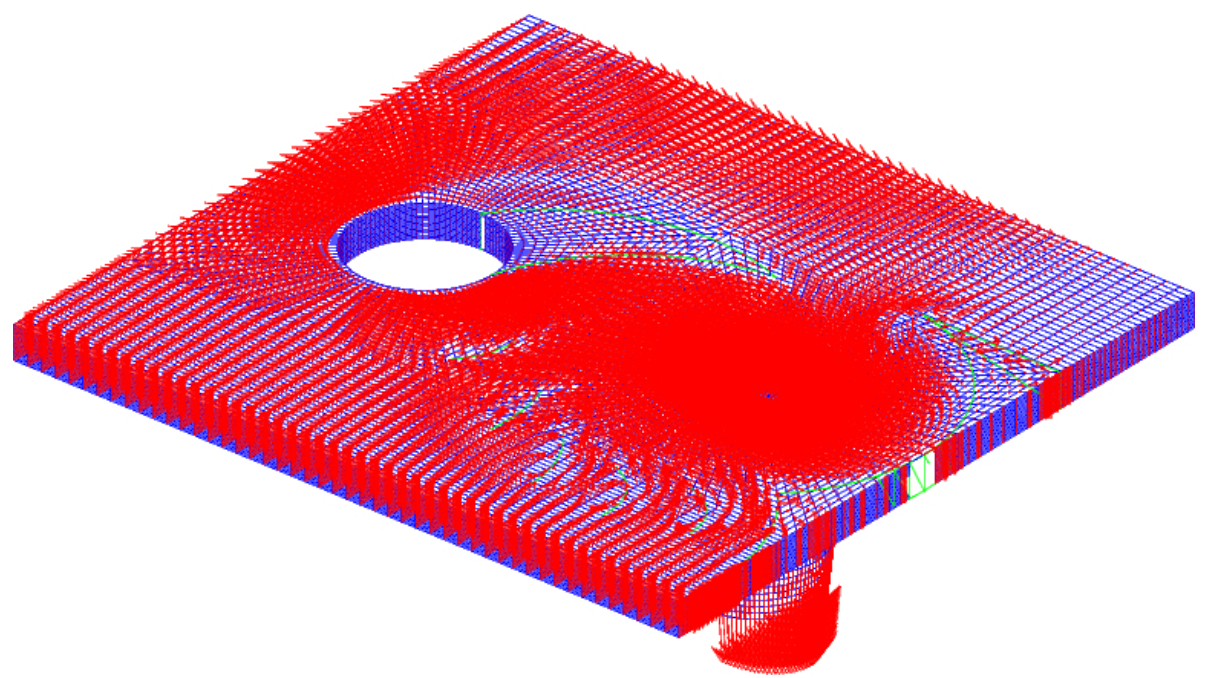

(b) With flow limiter.

Figure 11: Comparison of the velocity in LB-LOCA condition; mesh $M_{3}$ (164,160 elements); $\left(a_{S}=a ; L_{T}=1.0 \mathrm{~m}\right)$. 
LB-LOCA conditions

Mesh M3, L T $=1.0 \mathrm{~m}$

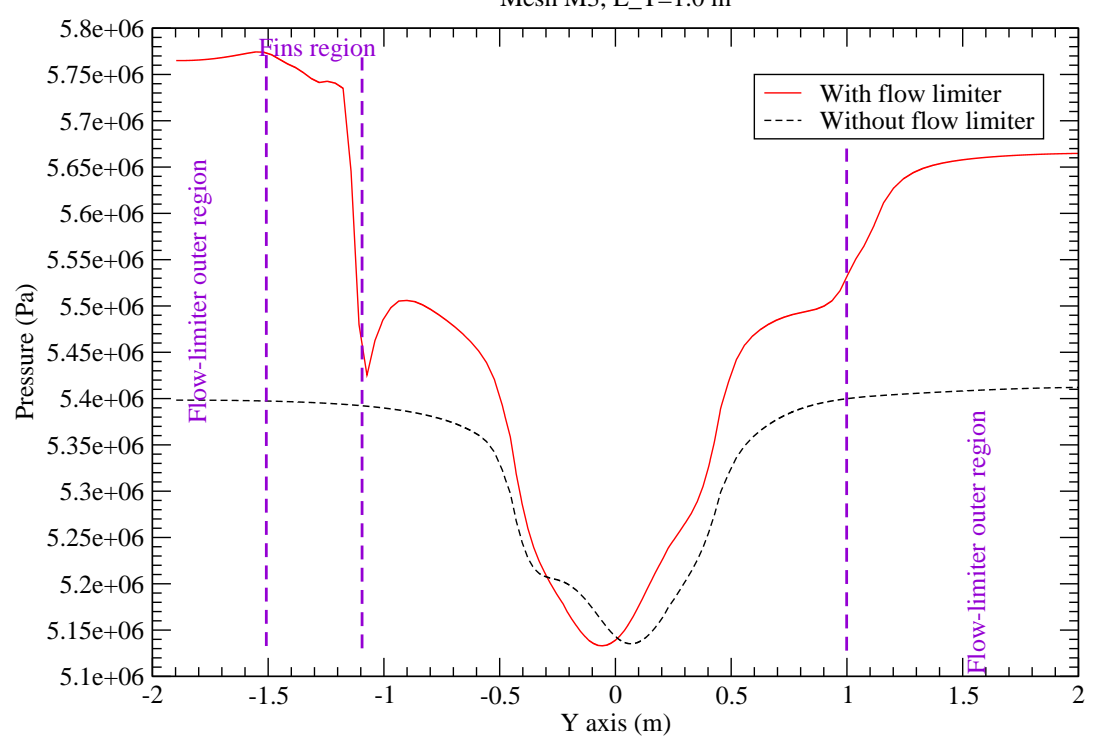

(a) Pressure.

\section{LB-LOCA conditions}

Mesh M3, L_T=1.0 m

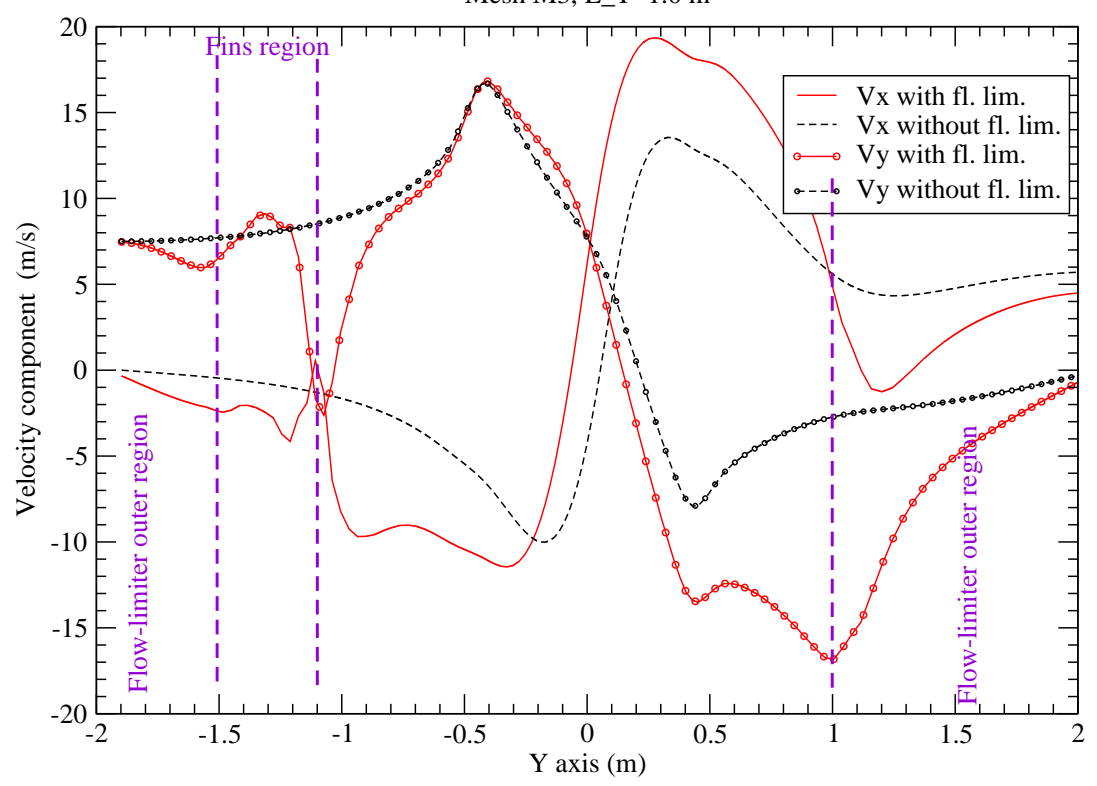

(b) Velocity $X / Y$-components.

Figure 12: Comparison of the pressure and velocity profiles in LB-LOCA condition; mesh $M_{3}$ (164,160 elements); $\left(a_{S}=a ; L_{T}=1.0 \mathrm{~m}\right)$. 


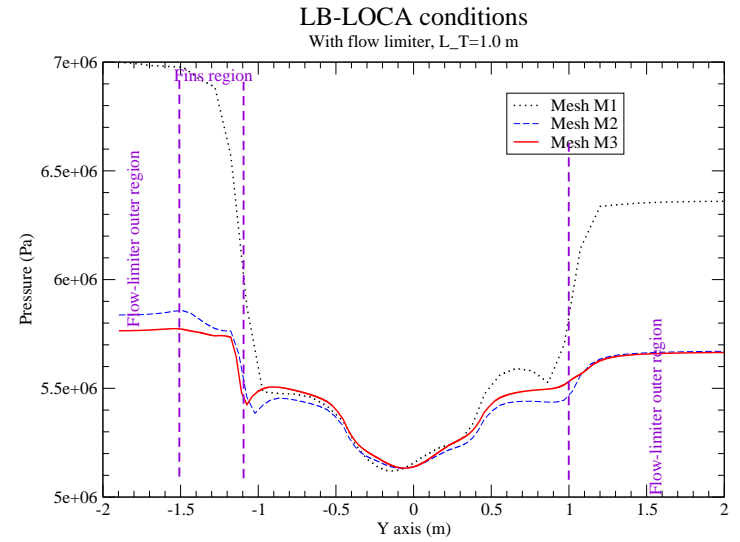

(a) Pressure.

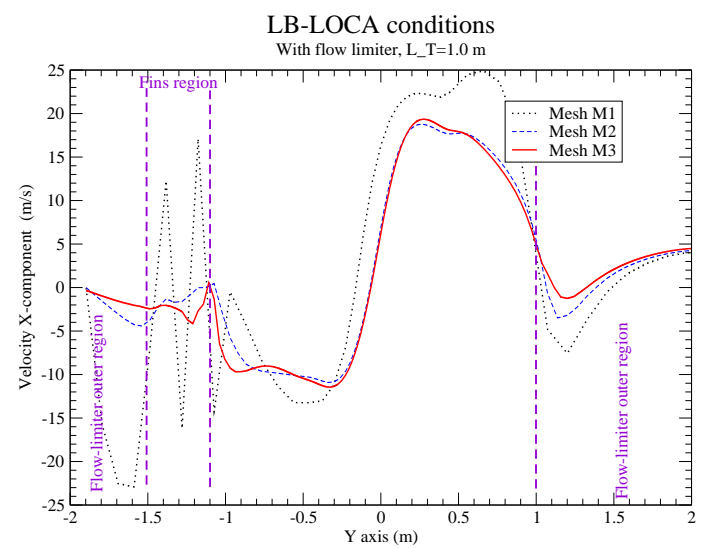

(b) Velocity $X$-component.

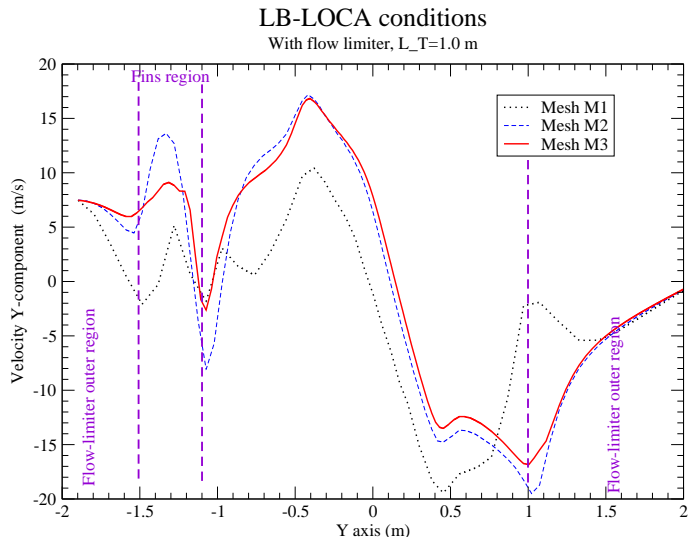

(c) Velocity $Y$-component.

Figure 13: Mesh convergence of the pressure and velocity profiles in LB-LOCA condition; $\left(a_{S}=a ; L_{T}=1.0 \mathrm{~m}\right)$. 
Fig. 13 shows the mesh convergence concerning the pressure and velocity profiles. Here again, the computation using the coarse mesh $M_{1}$ is clearly underresolved in space. In contrast, the profiles obtained with the meshes $M_{2}$ and $M_{3}$ are rather close, which indicates that the mesh convergence is almost reached.

\subsection{Two-phase flow}

To illustrate the GENEPI capacities to deal with two-phase flows, a computation has been done for the case of a two-phase reverse flow $\left(a_{S}=a ; L_{T}=\right.$ $1.0 \mathrm{~m}$ ) without flow limiter and meshes $M_{1}$ and $M_{3}$. For this computation, the enthalpy balance equation has been solved considering a turbulent Prandtl number of 0.5. CATHARE results provide the out-flow pressure value of 43.65 bar and the in-flow mixture specific enthalpy value of $1,291 \mathrm{~kJ} / \mathrm{kg}$ under a void fraction equals to 0.42 . The in-flow mass flow rate is unchanged. Figs 14 and 15 illustrate the void fraction field and Fig. 16 shows a comparison of the velocity fields for liquid and two-phase flows. As expected, as the mixture density is lower than the liquid one, the velocity increases.

375 In this case, the global GENEPI-computed two-phase pressure-drop coefficients are about $K_{M 1,2 \varphi}=3.2$ and $K_{M 3,2 \varphi}=3.0 ;$ a little less than (but not very different from) the one-phase ones: $K_{M 1}=3.9$ and $K_{M 3}=3.7$, cf Table 2 .

Fig. 17 shows a comparison of the pressure and velocity profiles along the line (0. $\mathrm{m},[-2.0 ; 2.0] \mathrm{m}, 0.1 \mathrm{~m}$ ) for two-phase and one-phase flows. As previously underlined, in the case of two-phase flows, the velocity magnitude is strongly increased as well as the pressure drop (about 3 bar). 


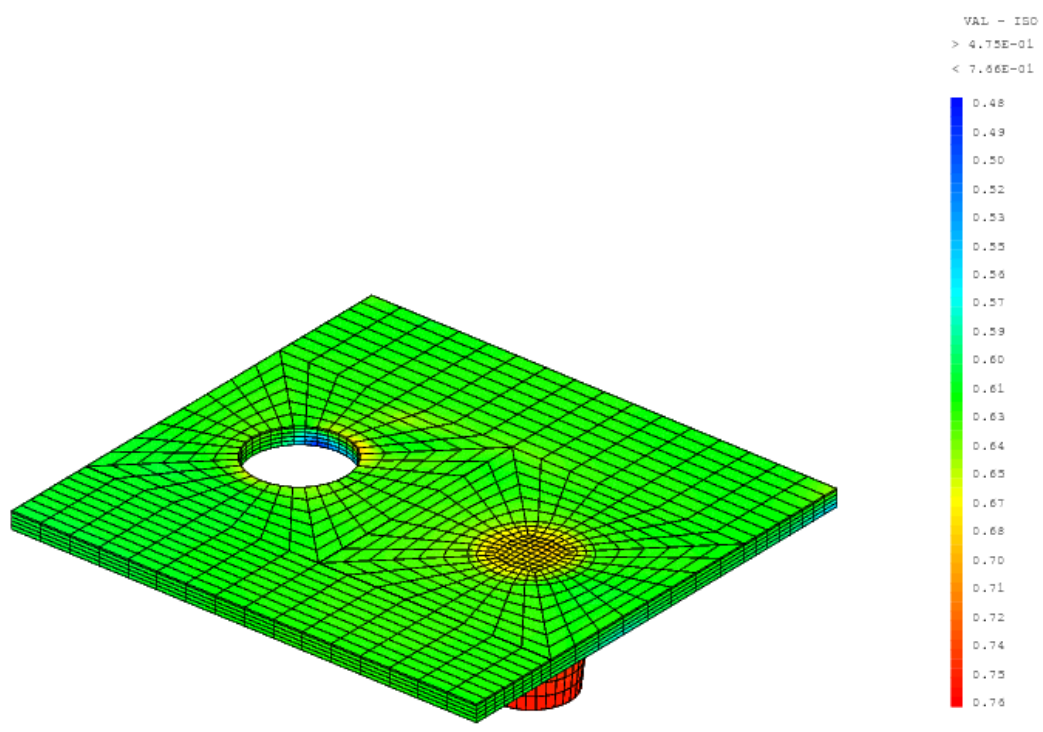

Figure 14: Two-phase flow CFD study of the in-vessel reverse flow without flow limiter: void fraction; mesh $M_{1}$ (6,080 elements); $\left(a_{S}=a ; L_{T}=1.0 \mathrm{~m}\right)$.

\section{LB-LOCA conditions}

Mesh M1, L_T $=1.0 \mathrm{~m}$

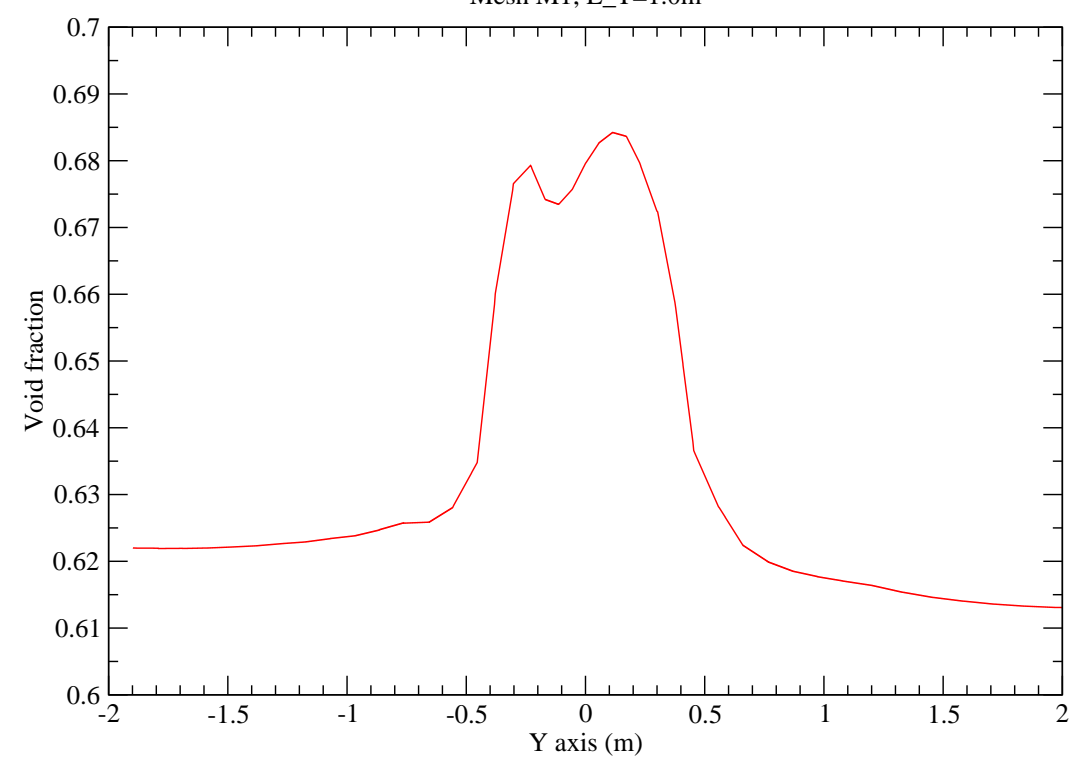

Figure 15: Two-phase flow CFD study of the in-vessel reverse flow without flow limiter: void fraction profile along the line $(0 . \mathrm{m},[-2.0 ; 2.0] \mathrm{m}, 0.1 \mathrm{~m})$; mesh $M_{1}$ (6,080 elements); $\left(a_{S}=a ; L_{T}=1.0 \mathrm{~m}\right)$. 


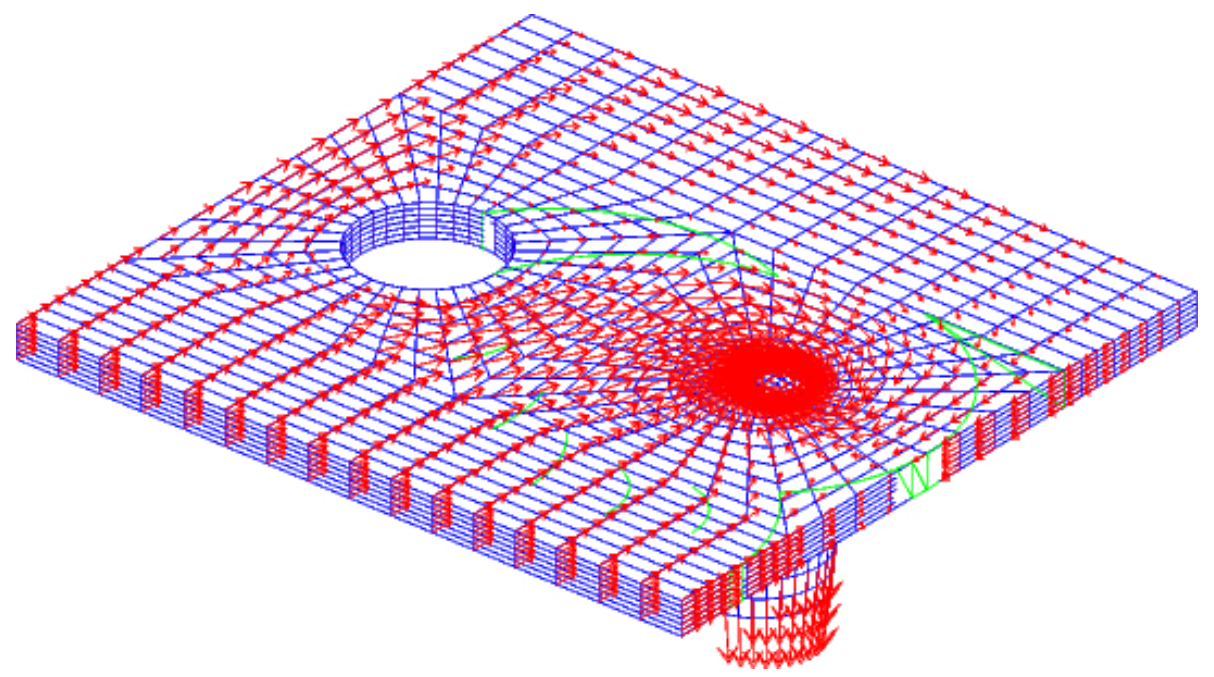

(a) Liquid flow.

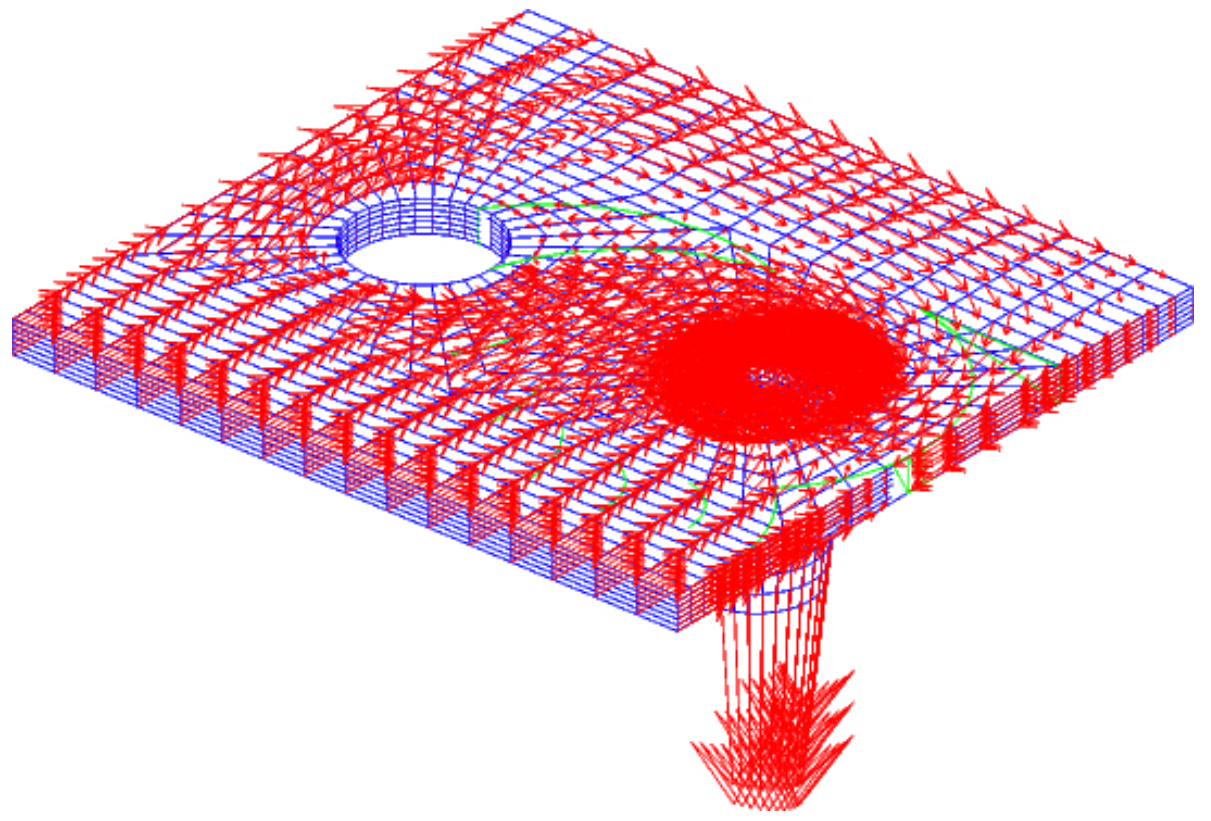

(b) Two-phase flow.

Figure 16: Two-phase flow CFD study of the in-vessel reverse flow without flow limiter: comparison of the velocity; mesh $M_{1}(6,080$ elements $) ;\left(a_{S}=a ; L_{T}=1.0 \mathrm{~m}\right)$. 


\section{LB-LOCA conditions}

Mesh M1, L_T $=1.0 \mathrm{~m}$

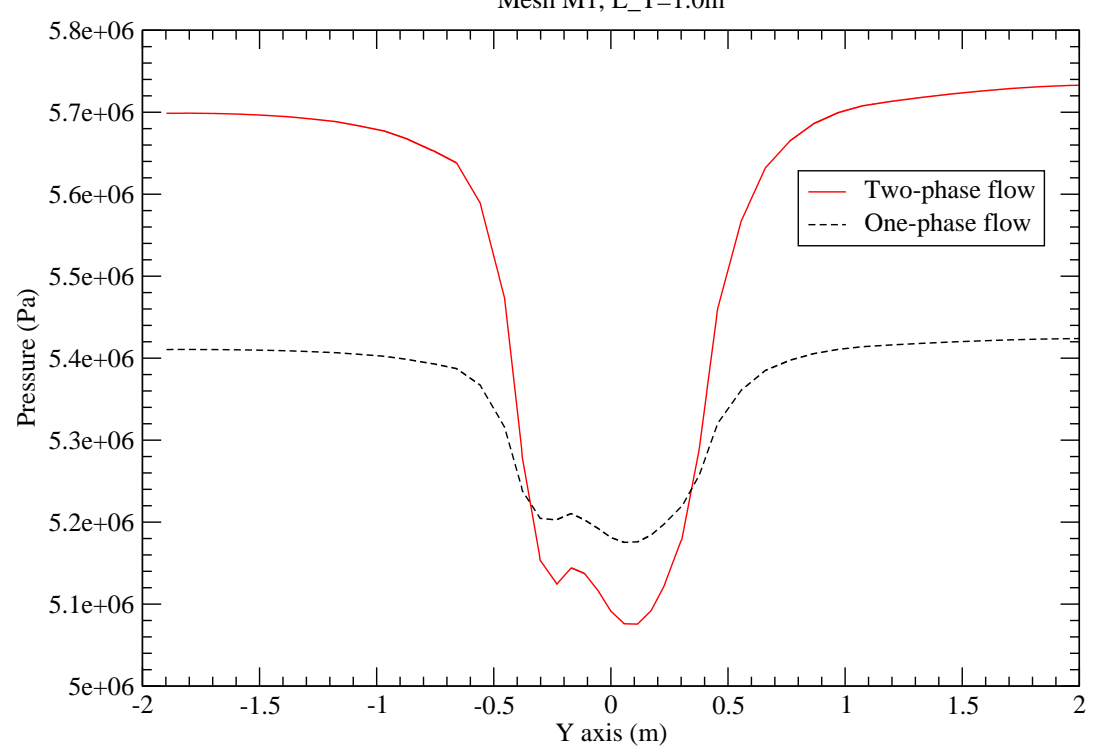

(a) Pressure.

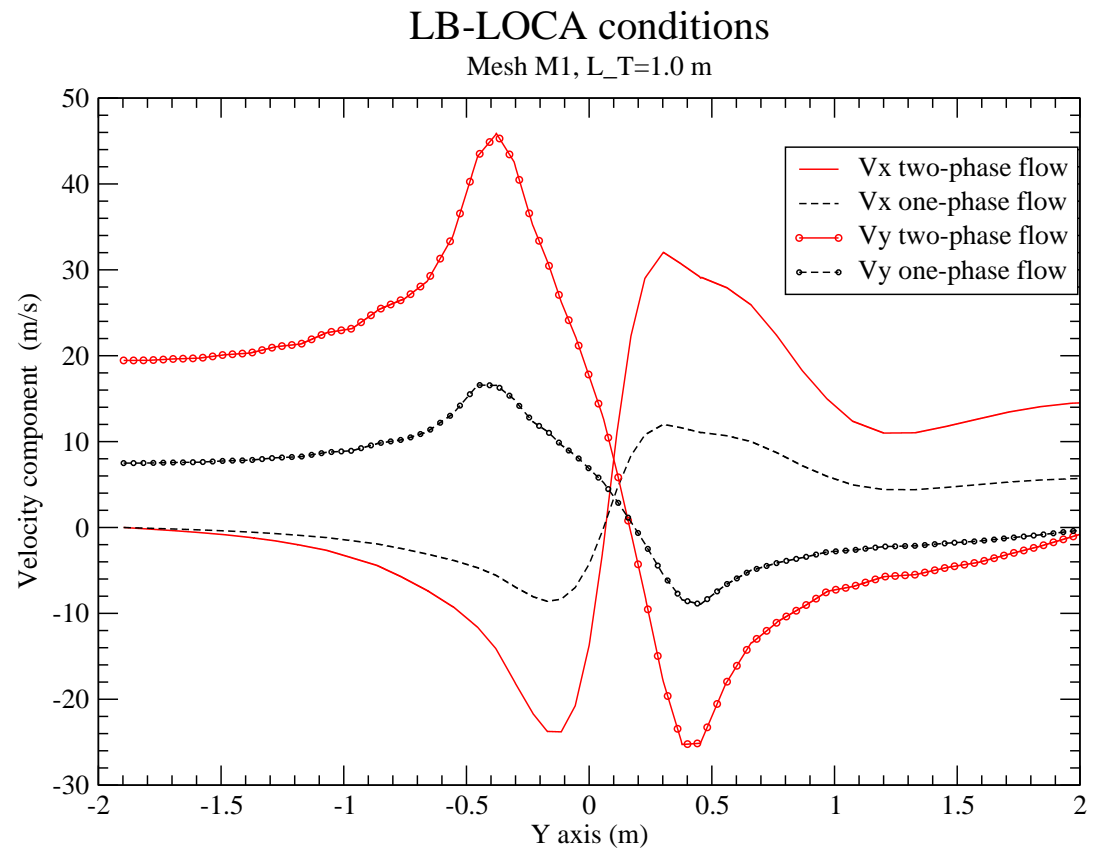

(b) Velocity $X / Y$-components.

Figure 17: Two-phase flow CFD study of the in-vessel reverse flow without flow limiter: comparison of the pressure and velocity profiles; mesh $M_{1}\left(6,080\right.$ elements); $\left(a_{S}=a ; L_{T}=\right.$ $1.0 \mathrm{~m})$. 


\subsection{CATHARE local pressure-drop coefficients}

Here, we try to evaluate the ad hoc CATHARE local pressure-drop coeffipatible with the above global CFD estimated values. Let us recall that the coefficients $K_{\text {in }}$ and $K_{\text {out }}$ are located at the junction between the down-comer volume element and the cold-leg axial elements of the CATHARE model, cf Section 5.1

- For the default flow direction and without in-vessel flow limiter, the global pressure-drop coefficients provided by GENEPI and CATHARE are similar $\left(K_{M 3} \in[-0.3 ;+0.1]\right.$ versus $\left.K_{g l, \text { cath }} \in[-0.3 ;-0.1]\right)$ giving confidence in the CATHARE local pressure-drop coefficient for nominaloperation flow direction defined by $K_{i n} \approx 1-1.8=-0.8[8]$.

- For the reverse flow direction and without in-vessel flow limiter, the values of the global pressure-drop coefficients provided by GENEPI ( $K_{M 3} \in$ $[3.6 ; 3.7]$ and $K_{M 3,2 \varphi} \approx 3.0$ ) may suggest that the CATHARE local pressuredrop coefficient for reverse flow direction are about $K_{\text {out }} \approx 7$. This can be a guideline for CATHARE studies as ones done in 8 .

- For the reverse flow direction and with in-vessel flow limiter, the CFD global pressure-drop coefficient is multiplied by almost a factor two $\left(K_{M 3} \in\right.$ $[3.6 ; 3.7] \rightarrow[5.4 ; 6.4])$. This leads to CATHARE local pressure-drop coefficient $K_{\text {out }} \approx 25$. This is higher than the lower values exhibited by parametric CATHARE computations 8 to get a beneficial effect of the invessel flow limiter on LB-LOCA transients: $K_{\text {gl,cath }} \approx 3.9$ for $K_{\text {out }} \approx 11.7$.

Concerning the reverse-flow case (LB-LOCA condition), two-phase-flow GENEPI simulations should refine the estimation of the global pressure-drop coefficients and, consequently, the CATHARE local pressure-drop coefficient $K_{\text {out }}$. 


\begin{tabular}{|c||c||c|}
\hline Flow direction & Without limiter & With limiter \\
\hline \hline Default $(1 \phi)$ & $K_{M 3} \in[-0.3 ;+0.1]$ & $K_{M 3} \in[0.7 ; 1.6]$ \\
GENEPI & $K_{\text {in }}=-0.8[8]$ & \\
CATHARE & $K_{\text {gl,cath }} \in[-0.3 ;-0.1]$ & \\
\hline Reverse & $K_{M 3} \in[3.6 ; 3.7]$ & $K_{M 3} \in[5.4 ; 6.4]$ \\
GENEPI $(1 \phi)$ & $K_{M 3,2 \varphi} \approx 3.0$ & Not computed here \\
GENEPI $(2 \phi)$ & $K_{\text {out }}=0.8[8] \rightarrow$ & $K_{\text {out }}=11.7[8] \rightarrow$ \\
CATHARE $(2 \phi)$ & $K_{\text {gl,cath }} \approx 1.3$ & $K_{\text {gl,cath }} \approx 3.9$ \\
& $K_{\text {out }}=7.0 \rightarrow K_{\text {gl }, \text { cath }} \approx 3.0$ & $K_{\text {out }}=25.0 \rightarrow K_{\text {gl, cath }} \approx 6.0$ \\
\hline
\end{tabular}

Table 3: Estimation of the CATHARE local pressure-drop coefficients $K_{\text {in }}$ and $K_{\text {out }}$ from the global CFD global pressure-drop coefficients $K_{M 3}$. The default flow direction is defined as the nominal-operation flow direction (from the cold leg to the down-comer). The reverse flow direction is defined as the opposite direction. The Schlichting coefficient is $a_{S}=a=0.047$ and $L_{T} \in\{0.3 ; 1.0\}$ m. $1 \phi$ : one-phase flow. $2 \phi$ : two-phase flow.

\section{Conclusions and perspectives}

In this paper, we have presented a CFD model of an in-vessel flow limiter to mitigate the consequences of a large-break loss of coolant accident in a pressurized-water reactor. The principle of this safety device is based on fins designed to create a strong flow vortex increasing the pressure drop toward the broken cold leg. A rough CFD model using a homogeneous relaxed equilibrium model of a liquid-vapour mixture and an immersed boundary approach has been set-up, allowing a less precise but fast estimation of the pressure drop following the geometry of the fins. Through 3D/1D up-scaling of a global pressure-drop coefficient, local pressure-drop coefficients can be provided to thermal-hydraulic system safety codes (here CATHARE), allowing the study of the in-vessel flow limiter effect on the thermal-hydraulic system.

One-phase and two-phase fluid CFD simulations have been run using the GENEPI code with a computation domain defined in coherence with the CATHARE 
model of a PWR. Parametric studies on the turbulence model lead to determine the range of the global pressure-drop coefficients depending on the direction of the flow and the presence of the flow limiter. Estimations of the CATHARE local pressure-drop coefficients have been done opening the way to 430 take into account the in-vessel flow limiter in a realistic manner. Moreover, the range of these estimated values is higher than the considered one in previously CATHARE studies [8, that is conservative from a point of view of safety analysis. Nevertheless, considering the limitations related to the turbulence model, this conclusion needs to be consolidated by body-fitted CFD studies with more precise turbulence models.

Some perspectives can be outlined about the improvement of this numerical model in order to proceed to the geometry optimization of the design of the flow-limiter fins. In particular, we can mentioned the space-interpolation scheme 440 across the boundary interface to reach the second order [15] and the definition of immersed-wall laws for RANS/large-eddy simulations. 


\section{References}

[11] IAEA, Advanced Reactors Information System (ARIS), https://aris. iaea.org/sites/overview.html, International Atomic Energy Agency.

[2] IAEA, Iaea-tecdoc-1624: Passive safety systems and natural circulation in water cooled nuclear power plants, http://www-pub.iaea.org/ MTCD/publications/PDF/te_1624_web.pdf, International Atomic Energy Agency (2009).

[3] IAEA, IAEA-TECDOC-62: Safety related terms for advanced nuclear plants, http://www-pub.iaea.org/MTCD/publications/PDF/te_ 626_web.pdf. International Atomic Energy Agency (1991).

[4] G.-M. Gautier, J.-F. Pignatel, R. Beraud, Development of the safety systems for a simplified, low pressure, medium sized PWR, in: 7th International Conference On Nuclear Engineering, no. ICONE-7211, Tokyo, Japan, 1999.

[5] G.-M. Gautier, Dispositif limiteur de débit inverse de fluide, Patent $n^{o} 88$ 12665 (1988).

[6] T. Shiraishi, Advances in Light Water Reactor Technologies, Saito, t. et al. Edition, Springer, 2011, Ch. The Advanced Accumulator: A New Passive ECCS Component of the APWR.

[7] I.-C. Chu, C.-H. Song, B. H. Cho, J. K. Park, Development of Passive Flow Controlling Safety Injection tank for APR1400, Nuclear Engineering and Design 238 (2008) 200-206.

[8] E. Stratta, M. Belliard, Thermal-hydraulic study of passive safety systems based on the hydraulic diode principle for the management of large-break loss of coolant accidents, in: 17th International Topical Meeting on Nuclear Reactor Thermal Hydraulics (NURETH-17), no. NURETH-20502, Xian, China, 2017. 
[9] F. Barré, M. Bernard, The CATHARE code strategy and assessment, Nuclear Engineering and Design 124 (3) (1990) 257-284.

[10] G. Geffraye, O. Antoni, M. Farvacque, D. Kadri, G. Lavialle, B. Rameau, A. Ruby, CATHARE 2v25_2: A single version for various applications, in: 13th International Topical Meeting on Nuclear Reactor Thermal Hydraulics (NURETH-13), Vol. 43 of INIS, IAEA, Kanazawa City, Ishikawa Prefecture, Japan, 2009.

[11] OECD-NEA, Assessment of CFD Codes for Nuclear Reactor Safety Problems - Revision 2, Tech. Rep. NEA/CSNI/R(2014)12, OECD-NEA (January 2015).

[12] V. Saul'ev, On the solution of some boundary value problems on high performance computers by fictitious domain method, Siberian Math. Journal 4 (4) (1963 (in Russian)) 912-925.

[13] L. Rukhovets, A remark on the method of fictive domains, Differential Equations 3 (4) (1967 (in Russian)) 114-121.

[14] S. Clerc, Numerical Simulation of the Homogeneous Equilibrium Model for Two-phase Flows., Journal of Computational Physics 161 (1) (2000) 354-375.

[15] C. Introïni, M. Belliard, C. Fournier, A Second Order Penalized Direct Forcing for Hybrid Cartesian/Immersed Boundary Flow Simulations, Computers \& Fluids 90 (2014) 21-41.

[16] M. Belliard, C. Fournier, Penalized direct forcing and projection schemes for navier stokes, C. R. Acad. Sci. Paris, Ser. I 348 (19-20) (2010) 11331136.

[17] M. Grandotto, P. Obry, Calculs des écoulements diphasiques dans les échangeurs par une méthode aux éléments finis, Revue Européenne des Eléments Finis 5 (1) (1996 [in French]) 53-74. 
[18] M. Grandotto, P. Obry, Steam Generator Two-Phase-Flow Numerical Simulation with Liquid and Gas Momentum Equations, Nuclear Science and Engineering 151 (2005) 313318.

[19] M. Belliard, I. Ramière, Fictitious domain methods for two-phase flow energy balance computations in nuclear components, International Journal for Numerical Methods in Fluids 68 (8) (2012) 939-957.

[20] G. S. Lellouche, B. A. Zolotar, Mechanistic Model For Predicting TwoPhase Void Fraction For Water in Vertical Tubes, Channels, and Rod Bundles, Special Report NP 2246-SR, EPRI (1982).

[21] N. Zuber, J. Findlay, Average Volumetric Concentration in Two-Phase Flow Systems, J. Heat Transfer 87 (4) (1965) 453-468.

[22] P. Gresho, S. Chan, On the theory of semi implicit projection methods for viscous incompressible flow and its implementation via finite element method that also introduces a nearly consistent matrix. i, theory, International Journal for Numerical Methods in Fluids 11 (5) (1990) 587-620.

[23] A. Brooks, T.-R. Hughes, Streamline upwind/petrov-galerkin formulations for convection dominated flows with particular emphasis on the incompressible navier-stokes equations, Computer methods in Applied Mechanics and Engineering 32 (1-3) (1982) 199259.

[24] H. Schlichting, Boundary Layer Theory, Mac Graw Hill, New York, USA, 1968.

[25] M. Hyman, Non-iterative numerical solution of boundary-value problems, Applied Scientific Research, Section B 2 (1) (1952) 325-351.

[26] I. Ramière, P. Angot, M. Belliard, A fictitious domain approach with spread interface for elliptic problems with general boundary conditions, Computer Methods in Applied Mechanics and Engineering 196 (4-6) (2007) 766-781. 
[27] P. Angot, C.-H. Bruneau, P. Fabrie, A penalization method to take into account obstacles in incompressible viscous flows, Numerische Mathematik 81 (4) (1999) 497-520.

[28] I. Ramière, Convergence analysis of the Q1-finite element method for elliptic problems with non-boundary-fitted meshes, International Journal for Numerical Methods in Engineering 75 (9) (2008) 1007-1052.

[29] T. Ye, R. Mittal, H. Udaykumar, W. Shyy, An accurate Cartesian grid method for viscous incompressible flows with complex immersed boundaries, Journal of Computational Physics 156 (1999) 209-240.

[30] J.-I. Choi, R. Oberoi, J. Edwards, J. Rosati, An immersed boundary method for complex incompressible flows, Journal of Computational Physics 224 (2007) 57-784.

[31] K. Taira, T. Colonius, The immersed boundary method: a projection approach, Journal of Computational Physics 225 (2007) 2118-2137.

[32] M. Linnick, H. Fasel, A high-order immersed interface method for simulating unsteady incompressible flows on irregular domains, Journal of Computational Physics 204 (2005) 157-192.

[33] B. Fornberg, A numerical study of steady viscous flow past a circular cylinder, Journal of Fluids Mechanic 98 (4) (1980) 819-855.

[34] D. Tritton, Experiments on the flow past a circular cylinder at low reynolds number, Journal of Fluids Mechanic 6 (1959) 547-567.

[35] B. Massey, J. Ward-Smith, Mechanics of Fluids, Taylor \& Francis, 2006, Ch. 7, p. 262.

545 [36] I. Idel'cik, Mémento des pertes de charge, 1999th Edition, Collection de la Direction des Etudes et Recherches d'Electricit de France, Eyrolles, 1960.

[37] P. Gresho, S. Chan, R. L. Lee, C. Upson, A modified Finite Element Method for Solving the Time-Dependent Incompressible Navier Stokes 
Equations (Part 1: Theory), Int. J. Num. Methods in Fluids 4 (6) (1984) $557-598$. 


\section{Nomenclature and acronyms}

Latin symbols

- $a_{S}$ : Schlichting model dimensionless constant

- $A_{e}$ : obstacle area intercepted by the element $e\left(m^{2}\right)$

- AGR: Advanced Gas-cooled Reactor

- AP1000: Advanced Passive PWR

- APR1400: Advanced Power Reactor

- ATMEA1: High-performance medium-power reactor of the ATMEA company (a joint-venture of AREVA and MITSUBISHI companies)

- BTD: Balancing Tensor Diffusivity method

- BWR: Boiling Water Reactor

- CANDU: CANadian Deuterium Uranium reactor

- $C_{d}$ : drag coefficient

- CFD: Computational Fluid Dynamic

565

- CP1: 900 MWe French PWR (Palier CP1)

- EPR: Evolutionary Power Reactor

- ESBWR: Economic Simplified Boiling Water Reactor

- g: gravity $\left(\mathrm{m} \mathrm{s} \mathrm{s}^{-2}\right)$

- G: mixture mass flux $(=\rho \mathbf{V})$

570

- $H$ : mixture specific enthalpy $\left({\left.\mathrm{J} k g^{-1}\right)}^{-1}\right.$

- $H_{l s}$ : saturated liquid specific enthalpy $\left(\mathrm{J} k g^{-1}\right)$

- IB: Immersed Boundary 
- IBC: Immersed Boundary Condition

- ISI: Immersed Spread Interface

575

- $L$ : latent heat $\left(\mathrm{J} g^{-1}\right)$

- $L_{T}$ : typical vortex length $(\mathrm{m})$

- $L_{w}$ : recirculation length $(\mathrm{m})$

- LB LOCA: Large Break Loss Of Coolant Accident

- $M_{i}$ : domain mesh

580

- $P$ : pressure $(\mathrm{Pa})$

- $P_{R}$ : Prandtl number $\left(=\frac{\mu_{T}}{\chi_{T}}\right)$

- PWR: Pressurized Water Reactor

- P4: 1,300 MWe French PWR (Palier P4)

- SCRAM: Safety Control Rod Axe Man

- SI: Safety Injection

- SUPG: Streamline Upwind Petrov-Galerkin method

- $t$ : time $(\mathrm{s})$

- V: mixture velocity $\left(\mathrm{m} \mathrm{s}^{-1}\right)$

- $\mathbf{v}_{R}$ : relative velocity (gas minus liquid, $\mathrm{m} \mathrm{s}^{-1}$ )

590

- VVER: Vodo-Vodiano Energuetitcheski Reaktor

- $x$ : static quality $\left(\equiv \frac{H-H_{l s}}{L}\right)$ 


\section{Greek symbols}

- $\epsilon$ : Penalty parameter $(0<\epsilon<<1)$

- $\chi_{T}$ : turbulent diffusion coefficient for the enthalpy balance equation $\left(\mathrm{kg} m^{-1} s^{-1}\right)$

- $\overline{\bar{\Lambda}}$ : two-phase friction tensor $\left(s^{-1}\right)$

- $\mu_{T}$ : two-phase turbulent dynamic viscosity $\left(\mathrm{N} \mathrm{s} \mathrm{m}^{-2}\right)$

- $\Omega_{e}$ : elementary volume of the element $e\left(\mathrm{~m}^{3}\right)$

- $\rho$ : mixture density $\left(\mathrm{kg} m^{-3}\right)$ 